\title{
Fuel Effects in Turbulent Premixed Pre-vaporised Alcohol/Air Jet Flames
}

\author{
J. Trabold ${ }^{1,2}$ (D) S. Hartl ${ }^{1} \cdot$ S. Walther ${ }^{1} \cdot$ A. Johchi ${ }^{2} \cdot$ A. Dreizler ${ }^{2} \cdot$ D. Geyer ${ }^{1}$ \\ Received: 6 December 2019 / Accepted: 13 May 2020 / Published online: 13 June 2020 \\ (c) The Author(s) 2020
}

\begin{abstract}
To study combustion fundamentals of complex fuels under well-defined boundary conditions, a novel Temperature Controlled Jet Burner (TCJB) system is designed that can stabilise both gaseous or pre-vaporised liquid fuels. In a first experimental exploratory study, piloted turbulent jet flames of pre-vaporised methanol, ethanol, 2-propanol and 2-butanol mixtures are compared to methane/air as a reference fuel. Complementary one-dimensional laminar flame calculations are used to provide flame parameters for comparison. Blowoff and flame length as global flame characteristics are measured over a wide range of equivalence ratios. For fuel rich conditions, blow-off limits correlate well with extinction strain rate calculations. Differing flame lengths from lean to rich conditions are explained partly by different flame wrinkling that is assessed using planar laser-induced fluorescence imaging of the hydroxyl radical (OH-PLIF). A study of Lewis-number effects indicates that they have substantial influence on flame wrinkling. Lean alcohol/air flames, opposed to methane/air, have a Lewis-number greater than unity. This impedes curvature development, which promotes relatively large flame lengths. In contrast, across stoichiometric conditions, all alcohol/air mixture Lewis-numbers decrease significantly. At such conditions, alcohol/air flames show alike or even larger wrinkling compared to methane/air flames. However, quantitatively, the differences in flame length and wrinkling observed among the flames can neither be explained alone by Lewis-number differences, nor other global mixture parameters available from 1D laminar flame calculations. This study shall therefore emphasise the need for more detailed experimental analyses of the full thermochemical state of laminar and turbulent flames fuelled with complex fuels.
\end{abstract}

Keywords Alcohol/air combustion · Biofuels · Turbulent combustion · Blow-off · Flame length $\cdot$ Extinction strain rate $\cdot$ Lewis-number effects $\cdot$ Flame surface density

J. Trabold

trabold@rsm.tu-darmstadt.de

1 Optical Diagnostics and Renewable Energies, Hochschule Darmstadt, Schöfferstrae 3, 64295 Darmstadt, Germany

2 Reactive Flows and Diagnostics, Technische Universität Darmstadt, Otto-Berndt-Strae 3, 64287 Darmstadt, Germany 


\section{Introduction}

Improving combustion technologies within short innovation cycles requires predictive mathematical models. For an improved phenomenological understanding and the validation of predictive models, comprehensive experimental investigations are needed, in particular for fuel flexible systems that also operate on renewable fuels. Renewable fuels including biofuels have the potential for reducing greenhouse gas emissions. Despite a growing market of electrical vehicles, biofuels are forecasted to make up about $90 \%$ of the total renewables in the transport sector in 2023, a share that even increased since 2017 (OECD 2018). Ethanol contributes by approximately two thirds of the grown biofuels and biodiesel, whereas hydro-treated vegetable oil (HVO) provides the remainder (OECD 2018). Developments in the derivation of 2nd and 3rd generation biofuels, as well as advancements in biotechnical engineering regarding isomers of the alcohols propanol and butanol, which have a reasonably high energy density, will continue to keep this an increasingly important research topic (Kohse-Höinghaus et al. 2010). Accordingly, a more detailed understanding of the relevant processes within the combustion of renewable fuels, e.g. combustion chemistry and the turbulence-chemistry interaction, is required. The studies summarised in the following emphasise this need.

In terms of alcohol combustion chemistry, Sarathy et al. (2014) reviewed properties of various alcohol isomers spanning from methanol to n-octanol.

Using a laminar counter-flow configuration, Veloo et al. (2010) experimentally and numerically compared methanol, ethanol and n-butanol flames and the corresponding n-alkane counterparts with respect to laminar burning velocities and extinction strain rates. Whereas ethanol and n-butanol behaved similar as their alkane counterparts, methanol and the corresponding alkane methane showed significant differences. This was attributed to different intermediate products dominating either chain branching or termination reactions.

Watson et al. (2017) investigated laminar premixed $\mathrm{C}_{1}-\mathrm{C}_{4}$ alkane and alcohol stagnation flames using laser-induced fluorescence (LIF) of $\mathrm{NO}$ and $\mathrm{CH}$, as well as particle tracking velocimetry (PTV) in a jet-wall experiment. They discussed the influence of molecular structures on NO formation. Alcohol mixtures led to less NO formation due to lower temperatures, as well as lower $\mathrm{CH}^{*}$ concentrations compared to their alkane counterparts.

Tamadonfar and Gülder (2015) explored the impact of fuel chain length on turbulence-chemistry interaction by using different alkanes. They used particle image velocimetry (PIV) and Mie scattering to study the structure of piloted turbulent premixed flames of the alkanes methane, ethane and propane. Equivalence ratios were selected to be at respective rich and lean conditions where they almost had identical unstretched premixed laminar burning velocities and bulk velocities. The results showed that from lean over stoichiometric to rich conditions, the mean turbulent flame stretch factor, flame length and thickness, flame surface density and fuel consumption rate varied differently for each fuel.

Carbone et al. (2017) extended the investigation of Tamadonfar and Gülder (2015). They explored the impact of fuel variations on turbulent premixed flame structures for different $\mathrm{C}_{1}-\mathrm{C}_{8}$ hydrocarbon fuels using PIV and chemiluminescence (CL) imaging for lean and stoichiometric conditions. Average flame lengths generally scaled with the laminar burning velocity. Methane, compared to larger molecular weight fuels, turned out to be an exception with regard to this scaling, having a significantly more reactive 
behaviour at lean conditions. It was hypothesised, that the different Lewis-numbers of the fuels control the resistance of the mostly positively stretched flames against local extinction, as the peak heat release rate increases for Le $<1$ (methane/air) and decreases for Le $>1$ (other studied fuels) mixtures, as already discussed earlier by Law et al. (1988).

In two studies, Guiberti et al. (2017a, b) investigated the blow-off stability for turbulent flow conditions using DME, CNG and LPG as fuels. The well-known Sydney/Sandia jet flame configuration was used to investigate the influence on blow-off caused by the pilot flame parameters adiabatic temperature, velocity, equivalence ratio, $\mathrm{H} / \mathrm{C}$ ratio and the heat release. Furthermore, the inhomogeneity of the mixture at the jet nozzle was varied through recess of an inner fuel tube. It was noted that although the pilot flame properties, such as adiabatic temperature and heat release, influence the blow-off, they had a minor influence compared to fuel variation.

To study turbulence-chemistry interaction for a variation of fuels, Smolke et al. (2017) compared lean methane to ethylene, propane, n-heptane and toluene flames using a piloted jet burner. Flow field and luminosity were recorded for constant laminar burning velocities, but varying turbulence intensities and heat losses towards a coflow with variable temperature. Reactivity and flame lengths showed high sensitivity to heat losses. Methane flames were longest and ethylene flames shortest. Whereas the influences of heat loss and Reynolds-number were reproduced by large eddy simulations (LES), fuel effects have not been predicted correctly.

The results of the referred studies indicate fuel effects are important parameters when modelling turbulence-chemistry interaction in combustion. To assist this development from the experimental side, piloted turbulent premixed flames fuelled with pre-vaporised alcohols are compared to methane/air flames as a reference in this study. To provide a consecutive range of $\mathrm{C}_{1}-\mathrm{C}_{4}$ alcohols, methanol $\left(\mathrm{CH}_{3} \mathrm{OH}\right)$, ethanol $\left(\mathrm{C}_{2} \mathrm{H}_{5} \mathrm{OH}\right)$, 2-propanol $\left(\mathrm{C}_{3} \mathrm{H}_{7} \mathrm{OH}\right)$ and 2-butanol $\left(\mathrm{C}_{4} \mathrm{H}_{9} \mathrm{OH}\right)$ are analysed in detail. Well-controlled inflow and boundary conditions are ensured by a novel piloted jet burner assembly, which was developed to allow for stabilising laminar flames starting at low flow rates up to turbulent flames with high bulk velocities. Liquid fuels are pre-vaporised and mixed with heated air in a periphery system, before they are supplied to the temperature controlled burner.

Laminar flame characteristics (Sect. 4.1), effective Lewis-numbers (Sect. 4.2), flame blow-off limits (Sect. 4.3), flame lengths (Sect. 4.4) and flame wrinkling (Sect. 4.5) of a series of turbulent premixed flames are investigated using 1D flame calculations, chemiluminescence imaging (CL) of electronically excited $\mathrm{CH}$-radicals as well as planar laserinduced fluorescence of the OH-radical (OH-PLIF).

\section{Burner Setup and Operating Conditions}

\subsection{Temperature Controlled Jet Burner}

Figure 1 shows two cross sectional views of the novel Temperature Controlled Jet Burner (TCJB) system. A stainless steel central jet tube (Fig. 1, right, depicted in blue) with an inner diameter of $D_{i, j e t}=11.4 \mathrm{~mm}$ and a length of $L=500 \mathrm{~mm}$ results in a non-dimensional tube length of $L / D_{i, j e t} \approx 43$. This ensures a fully developed pipe flow at the nozzle exit. The wall temperature of the jet tube is controlled by three adjacent nozzle heaters (Hotslot Mini) with a length of $150 \mathrm{~mm}$ each (Fig. 1, right, depicted in brown). Premixed 

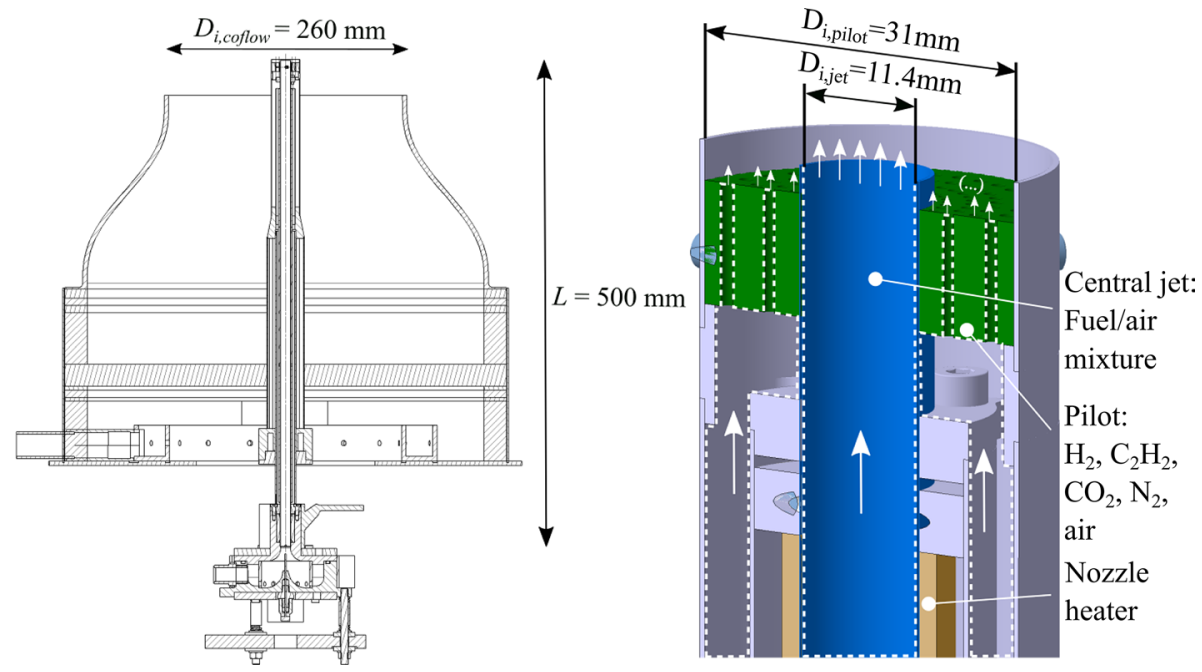

Fig. 1 Left: Cross section of the Temperature Controlled Jet Burner (TCJB). Right: Nozzle area with jet tube (blue) and pilot flame holder (green). The jet is heated by heating elements (brown)

fuel/air mixtures enter the burner through 16 circumferentially distributed holes at the base of the burner, which is heated with four additional custom designed heating jackets. The temperature is controlled over the whole burner assembly within $\pm 1 \mathrm{~K}$ using incorporated thermocouples (type $\mathrm{J}$ ) in combination with a number of PID controllers (Jumo cTRON 08 ) and electrically heated plates. Any cold spots are thereby avoided to prevent condensation of the pre-vaporised fuels. Thermocouple measurements at the nozzle exit indicated fluctuations of $\pm 1 \mathrm{~K}$ within the pre-vaporised fuel/air stream.

A pilot flame is required to stabilise the premixed jet flames at turbulent conditions. Here, a pilot configuration similar to the Sydney/Sandia jet burner is used (Masri et al. 1996, Dunn et al. 2007). An array of 144 individual laminar premixed Bunsen-type flames emanate at the exit of a co-annular tube that has an inner diameter of $\mathrm{D}_{i, p i l o t}=31 \mathrm{~mm}$. The Bunsen-type flames are arranged in four rings with 36 evenly distributed holes $(\varnothing=0.8,0.95,1.1,1.2 \mathrm{~mm})$ in each ring (Fig. 1, right, depicted in green). The reactants of the pilot flame are mixed upstream of the burner. In the present study, they consisted of hydrogen $\left(\mathrm{H}_{2}\right)$, acetylene $\left(\mathrm{C}_{2} \mathrm{H}_{2}\right)$, carbon dioxide $\left(\mathrm{CO}_{2}\right)$, air and nitrogen $\left(\mathrm{N}_{2}\right)$ at ambient temperature. The ratio of the first four components is varied to match the $\mathrm{C} / \mathrm{H} / \mathrm{O}$ atom ratio of the jet mixture at a fixed equivalence ratio of $\phi=0.7$. By additionally varying the $\mathrm{N}_{2}$ content, adiabatic flame temperatures of the pilots are also adjusted to fit those of the corresponding jet mixture at $\phi=0.7$. The gas composition ratios of the pilot flames used for the individual fuels are summarised in Table 4 in the Appendix. Corresponding heat release rates of the differently composed pilot flames and the respective adiabatic temperatures in the pilot for methane/air and the various alcohol/air flames of this study are listed in Table 1.

A coflowing stream of dry and filtered air with a bulk velocity of $u_{b u l k}=0.3 \mathrm{~m} / \mathrm{s} \mathrm{sur-}$ rounds the pilot flame to ensure well defined boundary conditions and to shield the flame. Following the design principles of Bell and Mehta (1988), a contoured nozzle (contraction ratio $2.89, D_{i, \text { coflow }}=260 \mathrm{~mm}$ ), that generates a uniform axial velocity profile at the exit, is employed to guide the coflow. 
Table 1 Fuel/air mixtures in the jet and respective heat releases and adiabatic temperatures of the pilot flames (always at an equivalence ratio of $\phi=0.7$ )

\begin{tabular}{lll}
\hline Jet & \multicolumn{2}{l}{ Pilot } \\
\cline { 2 - 3 } & Heat release (W) & Adiabatic temperature (K) \\
\hline Methane/air & 598 & 1873 \\
Methanol/air & 639 & 1920 \\
Ethanol/air & 646 & 1912 \\
2-Propanol/air & 650 & 1908 \\
2-Butanol/air & 651 & 1916 \\
\hline
\end{tabular}

The heat release of the pilot flame varies between 1.5 and $10 \%$ of that of the jet flame, depending on the operational conditions of the jet flame

\subsection{Pre-Vaporisation of Liquid Fuels}

Figure 2 shows the setup used for the supply of the pilot gas mixture, gaseous jet fuel/air mixture as well as the apparatus for the temperature-controlled pre-vaporisation of liquid fuel and subsequent mixture with air for the jet flame. A gear pump (Scherzinger GmbH 030-045-DM-25-2) circulates the liquid fuel in a loop and provides a constant, pulsation free upstream pressure needed for Coriolis-type mass flow controllers (Coriflow MFCs, Bronkhorst, accuracy $0.2 \%$ FS). Two Coriflow MFCs are used to cover a wider range of flow rates and Reynolds-numbers.

Downstream of the flow controllers, the liquid fuel is continuously vaporised in a combined evaporation and gas heater system (ADrop DV4, $4.5 \mathrm{~kW}$ electric). At atmospheric pressure, vaporisation rates of this system with maximum vapour temperatures of $573 \mathrm{~K}$ are up to $2 \mathrm{~kg} / \mathrm{h}$ for water. For liquids with lower specific enthalpy of

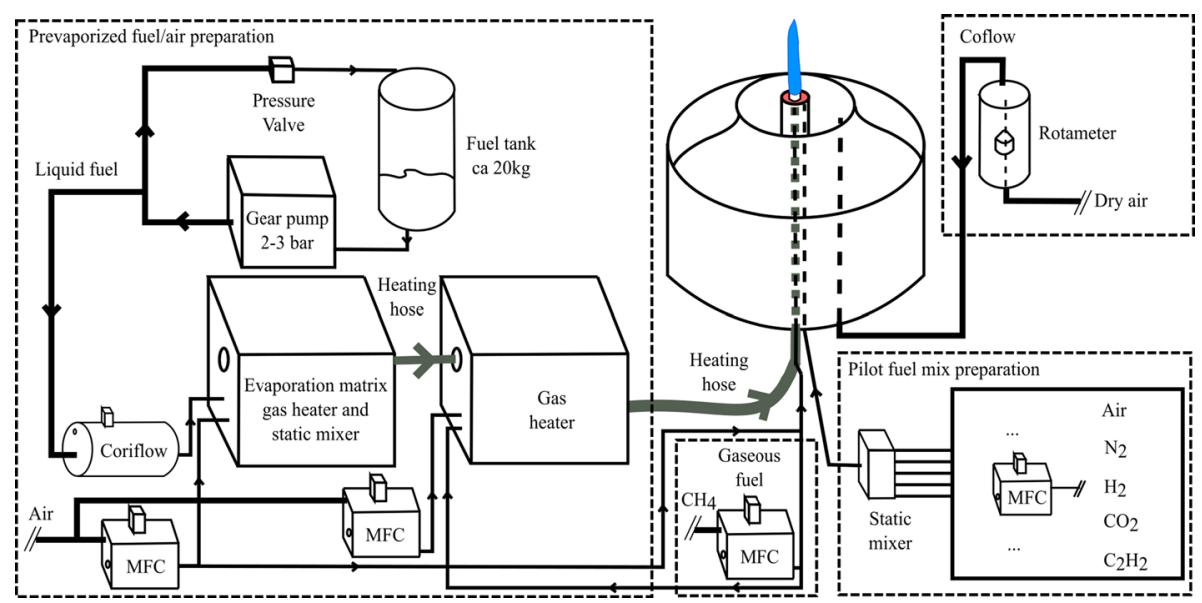

Fig. 2 Schematic of the periphery of the TCJB system. Left: Liquid fuels are pre-vaporised and premixed with hot air. Bottom-middle: Gaseous fuels can either enter through the heated path or directly. Right: Supply and mixing of pilot flame gases (bottom) and supply of air coflow (top) 
vaporisation, such as alcohols, the rates are accordingly higher, as for instance about 2.57 times higher for ethanol and 1.93 times for methanol. In parallel, that system can heat up $10 \mathrm{~kg} / \mathrm{h}(140 \mathrm{slpm})$ of air to $423 \mathrm{~K}$. The vaporised fuel and heated air are mixed in a high shear static mixer.

To allow for high flow rates, a second gas heater system (ADrop NH3) is used, which is capable of heating mass flows of $80 \mathrm{~kg} / \mathrm{h}$ (air) up to $493 \mathrm{~K}$. Air flows and pilot gases are controlled using calorimetric-type mass flow controllers (MFCs, Bronkhorst, accuracy $0.5 \% \mathrm{Rd}$ plus $0.1 \% \mathrm{FS}$ ). Heated hoses prevent condensation of the gaseous fuel/ air mixtures between the two pre-vaporisation systems and towards the burner system.

The setup allows to run flow rates up to the flame blow-off limits for a wide range of equivalence ratios and fuels. The highest operating condition of the present study, as an example, is a methanol/air flame near blow-off $\left(\operatorname{Re}_{b u l k}=61,000\right.$ at $\phi=1.5$; $\left.u_{\text {bulk }}=101 \mathrm{~m} / \mathrm{s}\right)$. The corresponding fuel flow rate is $6.23 \mathrm{~kg} / \mathrm{h}(0.13 \mathrm{l} / \mathrm{min})$, the air flow rate $29.88 \mathrm{~kg} / \mathrm{h}(644 \mathrm{slpm})$ and the resulting thermal power is approximately $45 \mathrm{~kW}$.

\subsection{Operating Conditions and Investigated Flame Characteristics}

The alcohols methanol, ethanol, 2-propanol and 2-butanol are selected as potential biofuel additives or surrogates of liquid fossil fuels. The study aims for investigating global and local flame characteristics in comparison to methane as reference fuel. In a first set of experiments, blow-off-limits are determined for each fuel/air mixture as a function of the equivalence ratio $(\phi)$. The equivalence ratio is varied in steps of 0.05 from lean $(0.8)$ to rich (1.5). Accordingly, maximum bulk velocities $\left(u_{b u l k, b o}\right)$ vary in dependence of the individual blow-off limit and span from 30 to $95 \mathrm{~m} / \mathrm{s}\left(\operatorname{Re}_{b u l k}=18,000\right.$ to 61,000$)$. In a second set of experiments, employing the flame chemiluminescence of $\mathrm{CH}^{*}$ as marker, flame lengths $\left(H_{f l} / D\right)$ are compared for a fixed Reynolds-number of $\operatorname{Re}_{b u l k}=18,000$ and the same range of equivalence ratios. Finally, flame surface densities $(\Sigma)$ are evaluated for lean and rich conditions $\left(\phi=0.9\right.$ and 1.05) at two different turbulence levels $\left(\operatorname{Re}_{b u l k}=12,000\right.$ and 18,000) from planar laser-induced fluorescence images of the $\mathrm{OH}$ radical (OH-PLIF).

For all alcohol/air mixtures, the gas temperature at the jet exit is $343 \mathrm{~K}$, whereas for methane/air mixtures, temperatures of $293 \mathrm{~K}$ and $343 \mathrm{~K}$ are investigated. All operating conditions are summarised in Table 2. Flame parameters of the mixtures are summarised in Table 3 in the Appendix.

The Reynolds-number was constant across the varying fuel/air mixtures in order to ensure similar turbulence levels and length scales in the turbulent jet flames. Small variations in the kinematic viscosity in between the alcohol/air mixtures lead to slightly different bulk velocities at the nozzle exit. Kinematic viscosities of methane/air mixtures are between 10 and 20\% larger (smaller) than those of the alcohol/air mixtures at 343 K (293 K). To set constant Reynolds-number at the nozzle exit, bulk velocities must be set accordingly larger (smaller).

For characterizing the fuel mixtures based on their thermal power, Fig. 3 shows two different conditions. The thermal powers $P_{\text {thermal,bulk }}$ at a jet Reynolds-number of 12,000 are shown on the left hand side, while $P_{\text {thermal,bulk }}$ at blow-off are shown on the right hand side. Note that the blow-off phenomenon of a piloted jet flame depends strongly on the pilot flame conditions. Similar to Coriton et al. (2017), a lean pilot flame was selected to ensure a low thermal power and temperature of the pilot flame. Thereby, the impact of the pilot on the jet flame is minimised. The lower adiabatic temperatures of the lean pilot flame also help to avoid potential heating damage to the steel nozzle. 


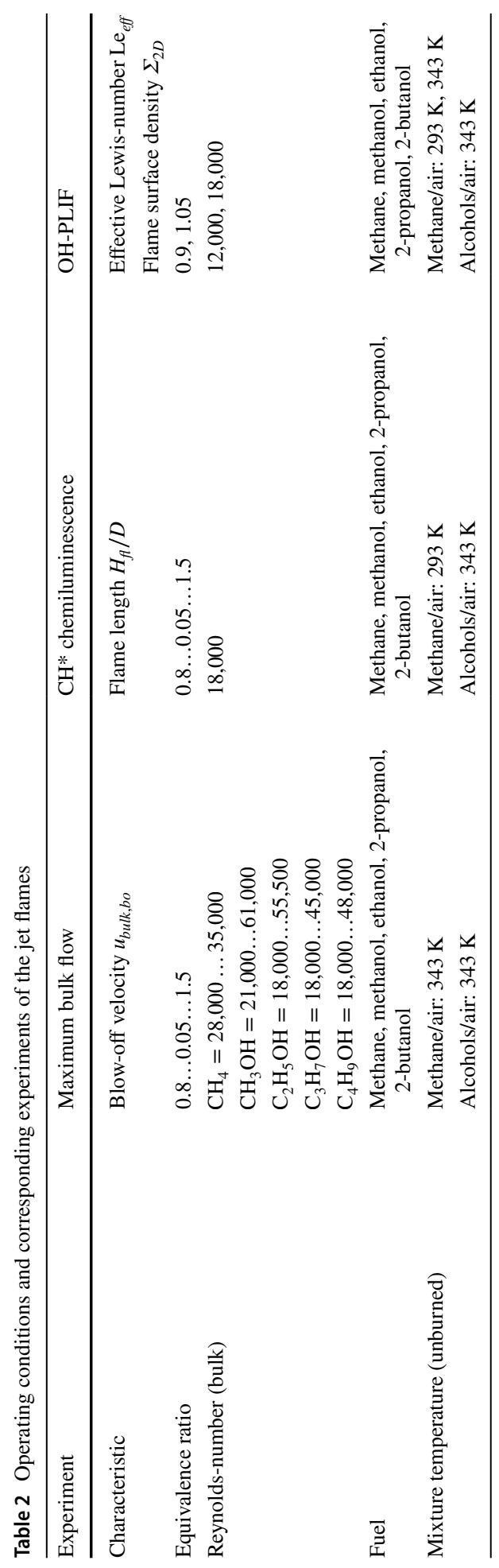



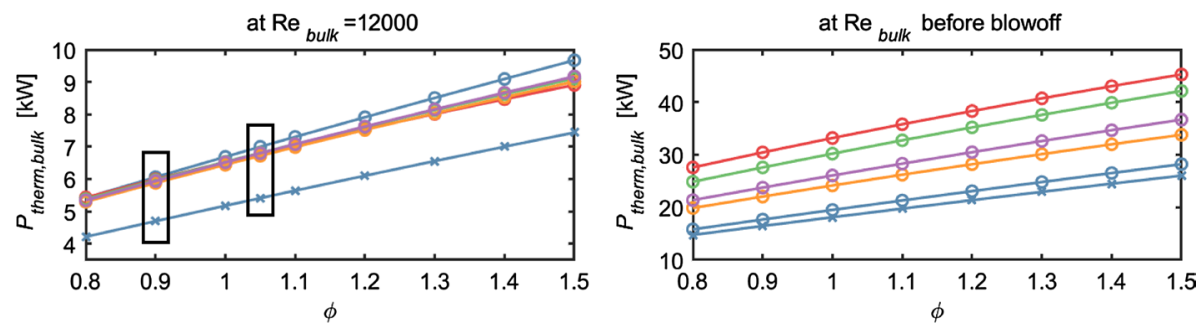

Fig. 3 Thermal power for varying bulk flow conditions. The equivalence ratios, at which flame curvature and flame surface density are analysed, are highlighted by the black boxes. Methane/air; $\left(\mathbf{x} T_{u}=293 \mathrm{~K}, \mathbf{0}\right.$

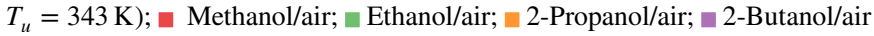

\section{Diagnostic Methods and Data Processing}

\subsection{Chemiluminescence Imaging}

In addition to spectrally broadband photography of the flames, chemiluminescence imaging (CL) of electronically excited $\mathrm{CH}$ radicals $\left(\mathrm{CH}^{*}\right)$ is used as a common marker for the location of reaction zones in hydrocarbon-fuelled flames (Donbar et al. 2000, Kojima et al. 2000). The strong emission peak of the A-X $(0,0)$ band near $431.4 \mathrm{~nm}$ is detected by a scientific CMOS camera (LaVision Imager sCMOS), equipped with a $50 \mathrm{~mm}$ F1.8 lens (Nikkor). Spectral crosstalk from $\mathrm{OH}^{*}, \mathrm{C}_{2} *$ and $\mathrm{CO}_{2} *$ (Samaniego et al. 1995, Kojima et al. 2000 ) is suppressed by a bandpass filter of $434 \pm 17 \mathrm{~nm}$ (BrightLine HC). The field of view (FOV) is $244 \times 206 \mathrm{~mm}^{2}$, resulting in a pixel resolution of $95 \mu \mathrm{m} /$ pixel. The optical resolution determined with a Siemens star is approximately $115 \mu \mathrm{m}(8.6 \mathrm{lp} / \mathrm{mm})$. Exposure times are $250 \mathrm{~ms}$ independent of the operating condition. To image the flames from nozzle to tip, two FOVs are monitored consecutively by traversing the burner in axial direction.

\subsection{OH-Planar Laser Induced Fluorescence}

Instantaneous flame contours are monitored by planar laser-induced fluorescence of the hydroxyl radical (OH-PLIF). Due to its high production rate in the mean reaction zone and its intense fluorescence signal, it is commonly used as a reaction zone marker (Sadanandan et al. 2008). The measurement system is shown in Fig. 4. A frequency doubled Nd:YAG laser (Spectra Physics, PIV 400, $300 \mathrm{~mJ}$ at $532 \mathrm{~nm}, 10 \mathrm{~Hz}$ ) is used to pump a dye laser (Sirah Lasertechnik GmbH, DoubleDye, Rhodamine 6G). After second harmonic generation of the dye laser radiation, pulse energies (approximately $2.9 \mathrm{~mJ}$ ) are reduced by beam splitters to $0.3 \mathrm{~mJ}$ to excite the $\mathrm{Q}_{1}(6)$ line of the $\mathrm{A}-\mathrm{X}(1,0)$ transition of $\mathrm{OH}$ at $283.01 \mathrm{~nm}$ in the linear regime. A laser light sheet with a cross section of $25 \times 0.2 \mathrm{~mm}^{2}$ is formed by an arrangement of cylindrical lenses. The sheet thickness is reported as the Full-Width-HalfMaximum (FWHM) and is measured with a beam monitor (WincamD, DataRay Inc.).

The OH fluorescence signal is captured by a UV lens (Sodern UV 100F/2.8) and imaged onto a CCD camera (Imager E-lite, LaVision $\mathrm{GmbH}$ ) equipped with Intensified Relay Optics (IRO, High-speed, LaVision GmbH). A band pass filter (BP300-325, Laser Components $\mathrm{GmbH})$ in front of the UV lens ensures that only the emissions of the $\mathrm{A}-\mathrm{X}(0,0)$ and $(1,1)$ bands are recorded. $\mathrm{OH}^{*}$ chemiluminescence and broadband flame luminosity are suppressed 
Fig. 4 Schematic of the excitation and detection side of the OH-PLIF setup

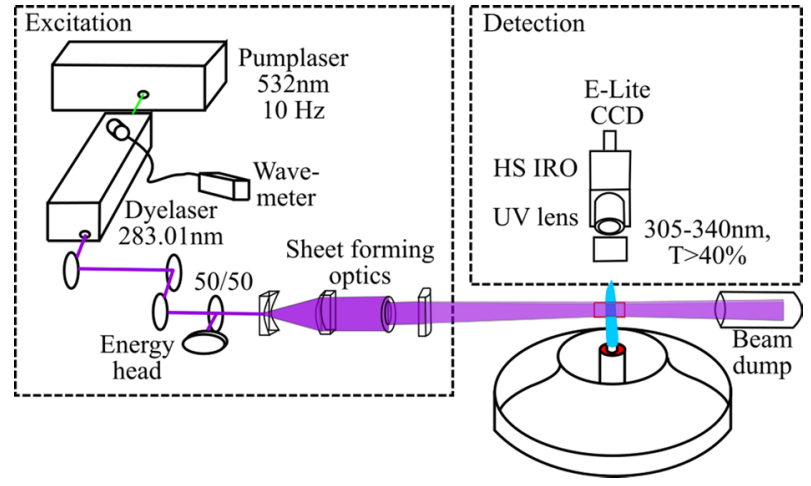

by gating the intensifier to $300 \mathrm{~ns}$. The PLIF detection system is arranged perpendicularly to the laser light sheet and the FOV is $24 \times 32 \mathrm{~mm}^{2}$. For measurements at different heights, the burner is traversed in axial direction $(x / D=1,3,5,7.5,10,13)$. While the FOVs at $x / D=1,3$ and 5 partly overlap, the FOVs further downstream spanning from $x / D=7.5$ to 13 do not overlap. The pixel resolution of the detection system is $23 \mu \mathrm{m} / \mathrm{pixel}$ and the optical resolution derived from imaging a Siemens star is approximately $110 \mu \mathrm{m}(9 \mathrm{lp} / \mathrm{mm})$. For each operating condition and axial location 2000 images are recorded. In addition, 200 images are recorded for the purpose of background correction while operating the laser off-resonant.

\subsection{Data Processing}

Flame lengths are derived by an average of 100 chemiluminescence images per fuel and flame condition. Two axial images are connected for a total view and outliers are filtered using a $5 \times 5$ pixel median filter. Following Pretzier (1991), an Abel inversion is performed to deduce the 2D time-averaged flame length from the 3D line-of-sight signal. In accordance with Carbone et al. (2017), flame lengths are represented by the axial location, where the normalised intensity of the radially integrated 2D signal dropped to $25 \%$ of the maximum.

Figure 5 presents the post-processing steps for the OH-PLIF data. After background correction, raw images (a) are filtered for intensity inhomogeneity using an averaged profile of the laser light sheet at each flame condition and height (Eitel et al. 2017) (b). Applying a threshold criterion based on the maximum gradient of the $\mathrm{OH}$ distribution, instantaneous images are segmented into zones of unburned and burned gases (binary image, (c)) (Nauert 2009). The interface between unburned and burned areas serves as an estimate of the flame front position. This flame front is fitted by cubic spline segments (d) using the methodology described by Sweeney et al. (2011). From the cubic splines, the curvature is deduced (Sweeney et al. 2011) (not shown). The mean reaction progress variable $c$ can be calculated from the mean of all binary images (e).

To derive a two-dimensional approximation of flame surface density $\Sigma_{2 D}$ (f), the approach by Donbar is used (Donbar et al. 2000):

$$
\Sigma_{2 D}=\lim _{\Delta x \rightarrow \delta_{f}} \frac{P}{\Delta x^{2}} .
$$

The perimeter $\underline{P}$ is the flame front spline length on a sub-pixel scale. All $\underline{P}$ are summed pixel-wise across the number of instantaneous realisations. The flame surface density field 
Fig. 5 Processing of $\mathrm{OH}-$ PLIF data. Raw images (a) are corrected for background and inhomogeneities of the laser light sheet (b). Images are binarised (c) and splines are fitted through the flame front (d). Mean reaction rate $c(\mathbf{e})$ is deduced from all binarised images and the flame surface density $\Sigma_{2 D}(\mathbf{f})$ is calculated from lengths of spline segments. Note that the pocket visible in (a) to (d) at $x / D=13$ is not visible in (f) because (f) represents a mean of 2000 images and the singular appearance of a pocket doesn't add significantly to the integrated $\Sigma_{2 D}$

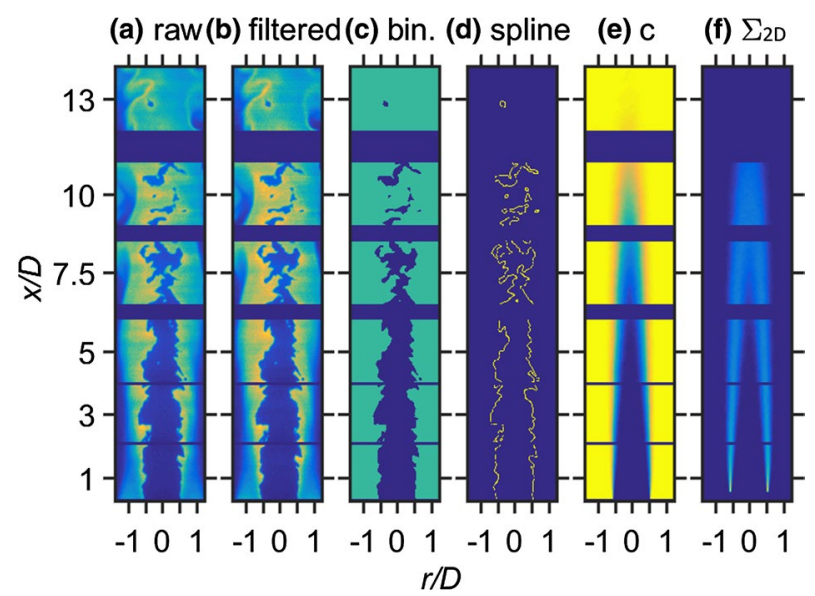

$\Sigma_{2 D}$ is then calculated by applying a moving-average filter across the summed- $\underline{P}$ image. An edge length of $\Delta x=0.5 \mathrm{~mm}$ is selected to ensure that the interrogation window is larger than the expected flame front thickness $\delta_{f}$ (refer to Sect. 3.4 for derivation), but at least five times smaller than the minimum flame brush thickness (derived from the mean reaction rate $c$ ), as suggested by Donbar et al. (2000). In a parametric study, it was confirmed that within these boundaries, $\Sigma_{2 D}$ is insensitive to variations in $\Delta x$. Lastly, the ensemble averaged flame surface density is computed by dividing the summed and filtered $\underline{P}$ matrix by the number of instantaneous realisations.

The flame surface density is an important parameter to compare different turbulent flames. It determines the mean reaction rate $\bar{w}$ (Trouvé and Poinsot 1994, Bray 1990, Shepherd 1996, Veynante et al. 1997):

$$
\bar{w}=s_{L} \cdot \rho \cdot I_{0} \cdot \Sigma,
$$

where $s_{L}$ is the laminar flame velocity, $\rho$ the density and $I_{0}$ the influence on the laminar burning velocity by stretch and curvature. To derive the impact of $\Sigma$ on the mean reaction rate of the individual flames in this study, the two-dimensional $\Sigma_{2 D}$ introduced above is radially integrated across the flame brush (similar to Filatyev et al. 2005, Shepherd 1996) according to the following equation:

$$
\Sigma_{2 D, i n t}^{*}=\frac{1}{2 \cdot n} \sum_{i=1}^{n} \int_{F O V, \text { l.b. }}^{F O V, r . b .} \Sigma_{2 D, i} d r,
$$

$\Sigma_{2 D, \text { int }}^{*}$ is referred to as the integrated flame surface density in the following. $n$ denotes all $\mathrm{OH}$-PLIF image realisations with a flame front at a given flame condition and FOV, $r$ the radius coordinate and $l . b . / r . b$. the left and right boundary of the FOV (the flame was always within the left and right boundaries). The multiplication by $\frac{1}{2}$ yields the mean of two flame branches observed by the intersecting laser light sheet. Note that $\Sigma_{2 D \text {,int }}^{*}$ is intentionally dimensionless when integrating the two-dimensional flame surface density (unit $\mathrm{mm}^{-1}$ ) over the $r$ dimension (unit $\mathrm{mm}$ ). Depending on axial position and operating condition, up to 2000 statistical independent realisations are considered to yield an ensemble-averaged value. Low sample numbers mainly result from regions at higher $x / D$ where combustion is 
almost complete and a decreasing number of samples contained a flame front which contributed to the statistics.

In order to assess the impact of fuel variations on the mean reaction rate $\bar{w}$ in equation 2 , the laminar burning velocity $s_{L}$ is calculated from one-dimensional (1D) unstretched laminar adiabatic flame simulations as discussed in the following section.

\subsection{One-Dimensional Laminar Flame Calculations}

Premixed 1D laminar unstretched adiabatic flame simulations of the varying fuel mixtures are performed for a wide range of equivalence ratios by using an in-house flame solver with a mixture average diffusion approach including thermal diffusion (Zschutschke et al. 2017). The methane/air flames are simulated using the GRI30 mechanism (Smith et al. 2019). For methanol/air, the mechanism by Li et al. (2007) is used. Ethanol/air mixtures are simulated using the recently developed ELTE mechanism by Olm et al. (2016). For 2-propanol/air and 2-butanol/air, the POLIMI/CRECK mechanism is selected (Frassoldati et al. 2012).

The range of equivalence ratios simulated spans from $\phi=0.8$ to 1.5. The initial temperature is $343 \mathrm{~K}$ and the pressure is atmospheric. Methane/air flames are additionally simulated for an initial temperature of $293 \mathrm{~K}$ to investigate the influence of pre-heating.

In addition to the laminar burning velocity $s_{L}$, the simulation provides information on the unburned mixture kinematic viscosity $v$, the density $\rho$, the laminar flame thickness $\delta_{f}=\left(T_{b}-T_{u}\right) /(d T / d x)_{\max }$ (Law 2010) and the effective Lewis-number $\left(\mathrm{Le}_{e f f}\right)$. The effective Lewis-number is calculated following an approach by Addabbo et al. (2002) and Law and Sung (2000). Mixture and flame specific parameters are summarised in Table 3 in the Appendix.

Using a 1D laminar counter-flow flame setup of the fuel/air mixtures against air, extinction strain rates are calculated at selected equivalence ratios. Therefore, the strain rate of the counter-flow flame is increased stepwise until extinction is reached by a rapid decrease in temperature. The information on varying extinction strain rates is used to support the interpretation of experimentally observed fuel-dependent blow-off limits.

\section{Results and Discussion}

In Sect. 4.1, laminar burning velocities and extinction strain rates are presented as relevant laminar flame characteristics to be included in the subsequent discussion of the turbulent flames. Section 4.2 introduces the calculation of the effective Lewis-number and the implications that the Lewis-number has on flame front wrinkling. Section 4.3 investigates the blow-off stability of the flames for various equivalence ratios of the jet mixture. Section 4.4 is devoted to the flame lengths for the different fuels at a fixed Reynolds-number of 18,000 and a range of equivalence ratios. Lastly, in Sect. 4.5, flame surface densities are presented for two equivalence ratios $(\phi=0.9,1.05)$ and Reynolds-numbers $\left(\operatorname{Re}_{\text {bulk }}=12,000,18,000\right)$.

\subsection{Laminar Burning Velocities and Extinction Strain Rates}

Calculated laminar burning velocities $s_{L}$ are presented for the different fuels in Fig. 6 . The magnitude of $s_{L}$ for a specific fuel/air mixture depends on the molecular structure of the fuel and intermediate products formed in the reaction zone (Veloo et al. 2010). While 
Fig. 6 Laminar burning velocities from 1D unstretched laminar adiabatic flame calculations. The equivalence ratios at which flame surface densities are analysed are framed. Methane/air; (x $T_{u}=293 \mathrm{~K}$, o $\left.T_{u}=343 \mathrm{~K}\right)$; Methanol/air; Ethanol/air; 2-Propanol/air; 2-Butanol/air

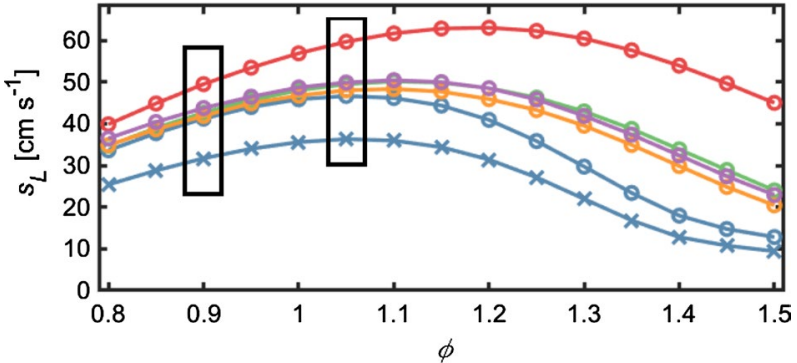

methanol/air flames mainly constitute intermediates intensifying chain branching, such as formaldehyde and hydrogen, methane/air combustion generates methyl radicals, which lead to chain termination. Between these two extreme cases, ethanol/air, 2-propanol/air and 2-butanol/air combustions generate a mixture of intermediates that balance chain branching and chain termination (Veloo et al. 2010). As a result, the alcohol/air mixtures show $s_{L}$ values in between methane/air and methanol/air. Notably, the $s_{L}$ for alcohol/air flames peak in the range of $\phi \approx 1.1-1.15$, which is slightly higher than for methane/air flames with its maximum at $\phi \approx 1.05$. According to Veloo et al. (2010), this difference is due to different sensitivities of alcohol/air flames with respect to chain branching reactions compared to alkane/air flames.

Laminar flame calculations are also used to derive extinction strain rates $a=\left(u_{1}+u_{2}\right) \cdot L^{-1}$, where $u_{1}$ and $u_{2}$ are the exit velocities of the two nozzles and $L$ is the separation distance. Results for methane/air (blue), methanol/air (red) and ethanol/air (green) flames against air are shown in Fig. 7 at three different equivalence ratios (dotted lines: $\phi=0.9$, dashed lines: $\phi=1.05$, solid lines: $\phi=1.5$ ). The right end of the lines mark the derived extinction strain rates of the mixtures. Whereas close to stoichiometry $(\phi=1.05)$ the highest absolute temperatures are reached, rich mixtures maintain a higher maximum temperature at higher strain rates and consequently reach higher extinction strain rates. This is due to additional heat produced by a back-supporting non-premixed flame that develops from residual hydrocarbons, which remain after the oxidation layer of the initial rich premixed flame and the opposite flow of air. The extinction strain rates can serve as indicators for analysing the flame blow-off experiments presented in Sect. 4.3. There, a similar scenario is observed from mixing between products of the jet flame at rich conditions and the surrounding lean pilot flame.

Fig. 7 Maximum flame temperature $T_{\max }$ from 1D laminar counter flow flame calculations of premixed fuel/air against air at $T_{u}=343 \mathrm{~K}$ and at varying strain rates. The right ends of the lines mark the defined positions of the extinction strain rates.

- Methane/air; Methanol/ air; Ethanol/air. Dotted lines: $\phi=0.9$, Dashed lines: $\phi=1.05$, Solid lines: $\phi=1.5$

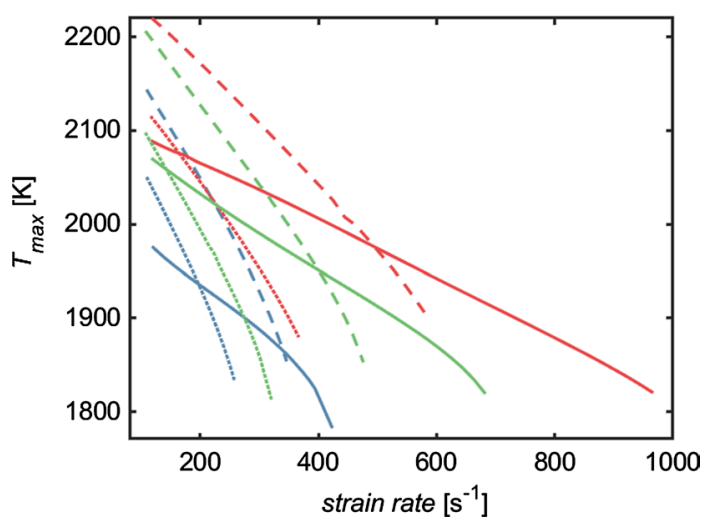




\subsection{Lewis-Number Effects}

Lewis-number (Le) effects are caused by different diffusion of heat and mass normal to the flame sheet. For Le $>1$, when heat exceeds mass diffusion, burning in concave flame segments (bowing towards products) is enhanced and burning in convex segments (bowing towards reactants) is weakened. This can be explained as increased preheating of the mixture and increased reaction rates on one side and lacking diffusion of unburned mass towards the flame on the other. For Le $>1$ this results in an overall smoothing of wrinkled flame structures (Law 2010). In contrast, Le $<1$ weakens the burning rate in concave curved regions and enhances the burning rate in convex curved regions, forming even sharper negatively curved cusps. This results in a cellularly unstable flame. Generally, wrinkling through diffusional-thermal instability is increased when Lewis-numbers decrease. Notably, the Lewis-number effects are most prominent at small scales comparable to the flame thickness Law (2010). The influence of non-unity Lewis-numbers caused by fuel variations on flame wrinkling and the evolution of curvatures in turbulent flames has also recently been highlighted by Alqallaf et al. (2019).

The effective Lewis-number ( $\mathrm{Le}_{\text {eff }}$ ) is a weighted average of the Lewis-numbers of the excess (lean: $\mathrm{O}_{2}$, rich: fuel) and deficient (lean: fuel, rich: $\mathrm{O}_{2}$ ) species in the reactants gas mixture (Addabbo et al. 2002, Law and Sung 2000). It is calculated using parameters available from 1D laminar flame calculations. Figure 8 presents effective Lewis-numbers $\left(\mathrm{Le}_{\text {eff }}\right.$ ) for a variety of equivalence ratios from $\phi \approx 0.8-1.5$ and different fuel/air mixtures.

Methane/air mixtures exhibit $\mathrm{Le}_{\text {eff }}$ slightly lower than unity at lean and slightly larger than unity at rich conditions. Because of the small deviation from unity, premixed methane/air flames are generally not prone to significant contributions by thermo-diffusive effects to flame wrinkling and hence mean reaction rate. Alcohol/air mixtures for stoichiometric and in particular for lean equivalence ratios feature $\mathrm{Le}_{\text {eff }}$ larger than unity and the magnitude increases with the molecular mass of the fuel. $\mathrm{Le}_{\text {eff }}$ is largest for the most lean 2-butanol/air mixture $(\approx 2.1)$. Accordingly, heat diffuses substantially faster than mass in such configurations and as discussed, flame wrinkling is thereby dampened. Across the stoichiometric point, the effective Lewis-numbers of alcohol/air mixtures decrease significantly. Hence, the flame front stabilising effect through dampening of curvatures decreases.

Fig. 8 Effective Lewis-numbers for a range of equivalence ratios calculated from results of $1 \mathrm{D}$ laminar flame calculations. Methane/air; Methanol/air; Ethanol/air; - 2-Propanol/air; 2-Butanol/air

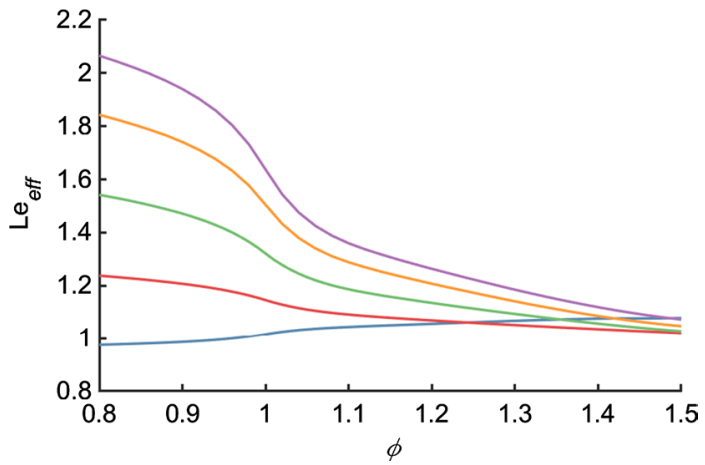




\subsection{Blow-off Stability}

Stability against blow-off is an important property for jet flames. To assess the blow-off stability limitations with the TCJB, the bulk velocity $u_{b u l k}$ of the jet is increased in steps of $\Delta u_{\text {bulk }}=0.7 \mathrm{~m} / \mathrm{s}$ until blow-off occurs. The blow-off is marked by the maximum velocity, at which the flame sustains downstream of the pilot region (region visible at the bottom of Fig. 5a) with an audible rumbling and in clear visual sight. Maximum bulk velocities at blow-off $u_{b u l k, b o}$ for the different fuel/air mixtures and at varying equivalence ratios spanning from $\phi=0.8$ to 1.5 are summarised in Fig. 9 .

Independent of the fuel, flames are more stable against blow-off with increasing $\phi$. This is expected to be due to the lean pilot flame, which particularly increases the blow-off limit of a fuel rich jet flame. In such a setup, a secondary non-premixed flame structure is established in close proximity of the rim and back-supports the premixed flame (partially-premixed flame structure). This flame is supported by the excess of different intermediates, such as hydrocarbons (Veloo et al. 2010) and/or $\mathrm{H}_{2}$ (Schneider et al. 2019), from the fuel rich jet flow and the surplus of oxygen in the lean pilot flame products (the inverse phenomenon was studied by Guiberti et al. 2017; Guiberti et al. 2017). The resulting partiallypremixed reaction zone counteracts the heat loss of the stretched zone of the shear layer (Lewis and von Elbe 1987; Farida et al. 2005). Results of the 1D simulation of the extinction strain rates discussed in Sect. 4.1 support this hypothesis, as an increase in extinction strain rate with equivalence ratio is reflected in the simulations.

Next, potential reasons for the differences between the fuel/air mixtures are discussed. Referring to findings of Guiberti et al. (2017), small differences in heat releases or adiabatic mixture temperatures in the pilot flames, as present in this study through constant operation at $\phi=0.7$ for each of the pilot flames (Table 1), do not pose a substantial influence to the blow-off stability. However, the relative differences of fuel-dependent extinction strain rates and maximum temperatures, as depicted in Fig. 7, are striking. These differences correlate well with the magnitude of blow-off velocities of the jet flames at slightly rich and very rich conditions.

At lean conditions, methane/air mixtures do exceed the alcohol/air mixtures in blowoff velocity, despite lower extinction strain rates and maximum flame temperatures in the correlating laminar strained 1D simulation (see Sect. 4.1). Therefore, in comparison to the rich jet flames, different mechanisms must be responsible for the varying blow-off behaviour among the fuels at lean conditions. Guiberti et al. (2017) conclude that stability variations against blow-off among different fuels are dominated by fuel-dependent reactivity properties. Notice here, that for the lean conditions discussed, methane/air is closer to its maximum laminar burning velocity at $\phi=1.05$ than the alcohol/air mixtures, which peak

Fig. 9 Bulk velocity $u_{\text {bulk,bo }}$ at blow-off for $T_{u}=343 \mathrm{~K}$ in dependency on the equivalence ratio. Methane/air; Methanol/ air; Ethanol/air; 2-Propanol/ air; 2-Butanol/air

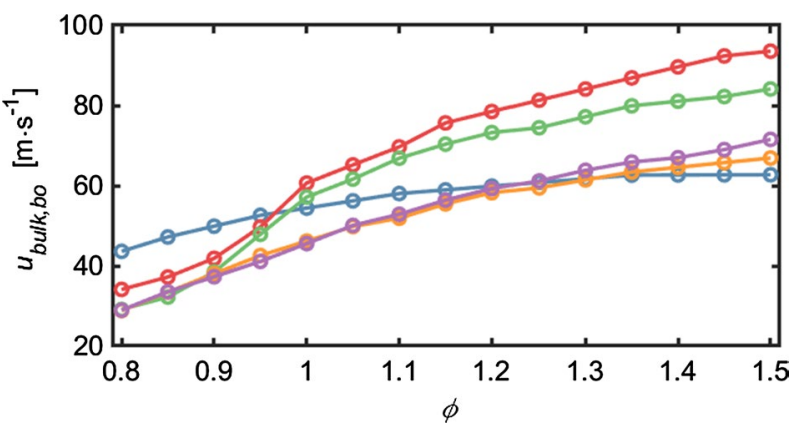


between $\phi=1.1$ and 1.2. Furthermore, Carbone et al. (2017) pointed out that compared with longer hydrocarbons, methane/air had significantly higher chemiluminescence intensities and therefore concentration of radicals at lean conditions in the region up to approximately $x / D=6$. This would also be a supporting factor for a higher stability against blowoff. Carbone et al. (2017) hypothesised that the more reactive behaviour by methane/air resulted from Lewis-number effects. As shown in Sect. 4.2, methane/air has a substantially lower Lewis-number at lean conditions, which is beneficial for the development of flame wrinkling. However, differences between the fuels observed for the axial progression of flame wrinkling start only downstream of $x / D=4$ for lean conditions, as will be shown in Sect. 4.5. Because this is beyond the near-nozzle region, which is most important for flame stabilisation, it is not clear whether this contributes significantly to the higher blowoff velocities for methane/air flames.

\subsection{Chemiluminescence and Flame Length}

In the following, the flame length is studied as a global flame property. To provide a visual impression, the photographs in Fig. 10 (black background) show the broadband chemiluminescence (CL) of slightly lean, slightly rich and rich flames at a constant jet Reynoldsnumber of $\operatorname{Re}_{b u l k}=18,000$.

In order to visualise mean distributions of the reaction zones, the corresponding images of the Abel-inverted $\mathrm{CH}^{*} \mathrm{CL}$ (blue background) at the same conditions are shown at the identical scale as the photographs next to them. Lens aperture and gating time of camera system were kept constant, such that local $\mathrm{CH}^{*}$ intensities of the flames can be used for relative comparisons. In accordance to Carbone et al. (2017), relative flame lengths of the fuels are extracted from the radially integrated $\mathrm{CH}^{*}$ intensities by using the axial value, where the normalised intensity dropped to $25 \%$ of the maximum intensity (in downstream direction). The flame lengths normalised by the jet diameter, $H_{f l} / D$, for $\operatorname{Re}_{b u l k}=18,000$ are shown in Fig. 11 (top) as a function of the equivalence ratio.

Methane/air mixtures show a minimum flame length at $\phi=0.9$, with a strong increase towards fuel rich conditions. Figure 11 reveals that the two different temperatures of the methane/air fuel mixture only have a minor influence on the flame length. This holds true in particular for equivalence ratios up to 1.2. For reasons of brevity, the different temperatures are therefore excluded from the following discussion. The alcohol/air mixtures show a different behaviour, with a minimum flame length at fuel rich conditions (depending on fuel, minimum located between $\phi=1.3$ and 1.45). Differences in flame lengths between

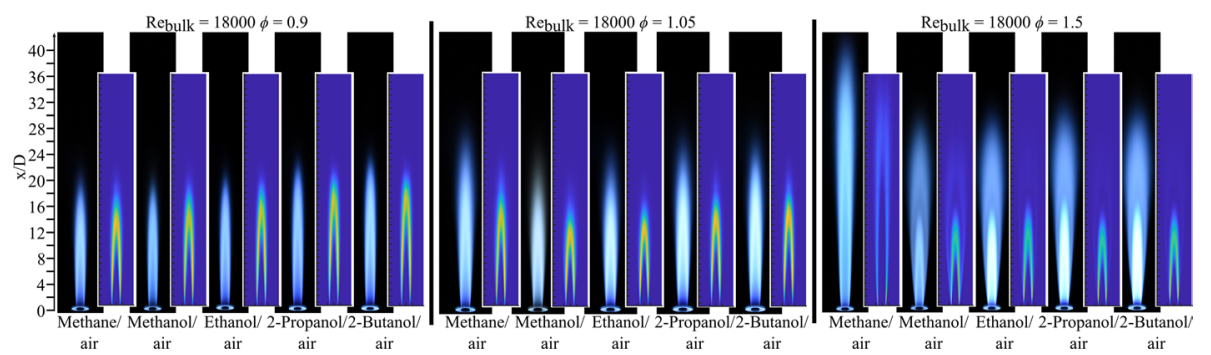

Fig. 10 Chemiluminescence at bulk Reynolds-number $\operatorname{Re}_{\text {bulk }}=18,000$, unburned mixture temperatures $T_{u}=343 \mathrm{~K}$ and equivalence ratios $\phi=0.9,1.05$ and 1.5 (left to right). Black background images show broadband CL. Blue background images show bandpass filtered $\mathrm{CH}^{*}$ emissions $(434 \pm 17 \mathrm{~nm})$ 
Fig. 11 Top: Normalised flame lengths at $\operatorname{Re}_{\text {bulk }}=18,000$ over equivalence ratio $\phi$. Bottom: Normalised bulk velocity $u_{\text {bulk }} / s_{L}$ at the same conditions. - Methane/air; Methanol/air; Ethanol/air; - 2-Propanol/ air; 2-Butanol/air. Preheating temperatures of the mixtures are either $293 \mathrm{~K}(\mathbf{x})$ or $343 \mathrm{~K}(\mathbf{o})$
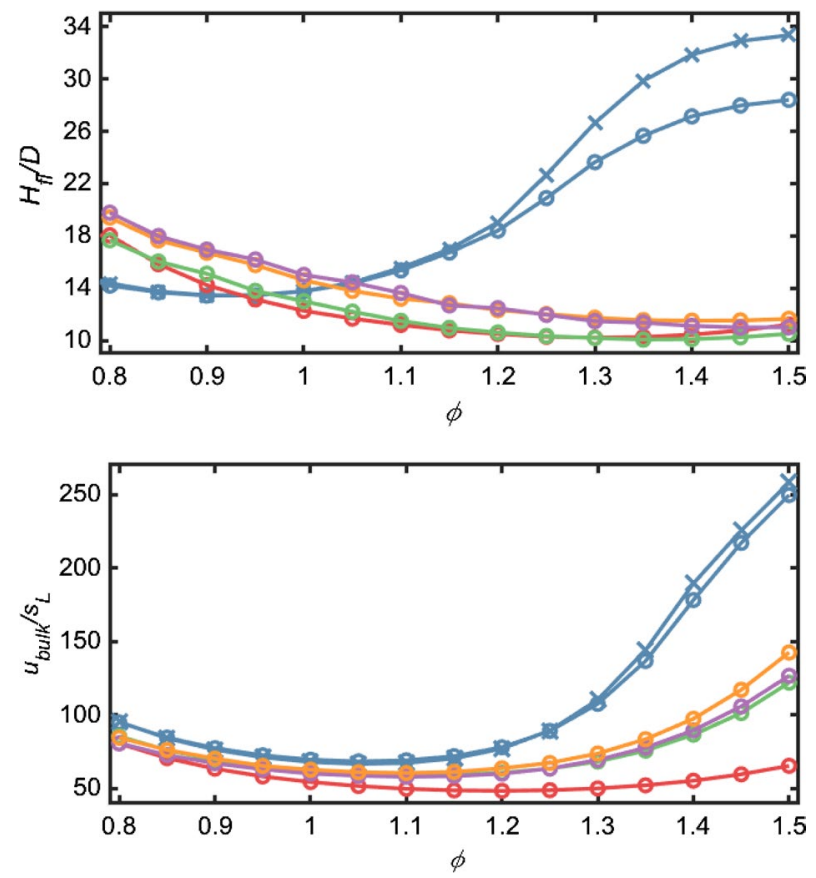

the alcohol/air mixtures are small compared with their difference to the corresponding methane/air flames.

The difference to methane/air flames at fuel rich conditions can be explained in part by corresponding laminar burning velocities and kinematic viscosities. As shown in Fig. 6, laminar burning velocities for fuel rich conditions are lowest for methane/air, with discrepancies of up to $30 \%$ to the lowest alcohol/air mixture at $\phi=1.5$. To summarise these effects, Fig. 11 (bottom) shows the corresponding normalised bulk velocities $u_{b u l k} / s_{L}$. The ratios between $u_{b u l k} / s_{L}$ of methane/air and methanol/air, as well as between methane/air and the other alcohol air mixtures, are 3.8 and 1.7-2.0 respectively. Considering the differences in between the alcohol/air mixtures, it is striking that the substantially smaller ratio of $u_{\text {bulk }} / s_{L}$ for methanol at the richest conditions is not reflected in a flame length differing significantly from the ones of the other alcohols. Apparently, a scaling solely based on bulk velocities and laminar burning velocities is not sufficient to explain the different flame lengths at rich turbulent conditions, as stated possible for lean conditions and fuels with similar Lewis-numbers by Carbone et al. (2017).

The flame wrinkling, as another relevant parameter for the mean reaction rate and subsequently flame length, is discussed in the following.

\subsection{Local Flame Topologies}

First, instantaneous locations of flame contours are discussed. This includes a brief discussion of hydrodynamic instabilities. Second, integrated flame surface densities are extracted and used to assess mean reaction rates of the flames. 


\subsubsection{Instantaneous Flame Fronts and Hydrodynamic Instabilities}

Typical instantaneous OH-PLIF images of the five different fuels are presented in Fig. 12 for an equivalence ratio of $\phi=1.05$ and a bulk Reynolds-number of $\operatorname{Re}_{\text {bulk }}=12,000$. For each fuel, six arbitrarily selected individual images recorded at the six axial positions are assembled to yield a global impression of instantaneous flame structures. The $\mathrm{OH}$ radical is formed in the reaction zone and extends into the post flame regions. Accordingly, a steep increase of the $\mathrm{OH}$ radical is an indicator for the reactant side of the flame fronts.

Close to the nozzle exit $(x / D=0.5), \mathrm{OH}$ is distributed almost homogeneously around the central jet. This region is attributed to hot products of the pilot (operated at $\phi=0.7$ ). The influence of the pilot is observed up to axial locations of approximately $x / D=2$ for all fuels. The intense and narrowly distributed OH-PLIF signal up to $x / D=1$ at the edge of the jet's core indicates that all flames stabilise close to the nozzle exit within the pilot region. A subsequent spreading of the jet, associated with a radial expansion of the $\mathrm{OH}$ region, is visible for all flames. Note that the reaction zone is predominantly located directly at the premixed fuel/air jet, while the post flame zones are mostly visible towards the larger radii. Farther downstream, enclosed pockets appear in the $2 \mathrm{D}$ intersection view (example for pockets of unburned gas: methanol/air flame at $x / D \approx 7.5$; example for pocket of burned gas: ethanol/air flame at $x / D \approx 5$ ). These pockets most probably result from intermittent 3D structures and are also included in the flame surface density study discussed below.

The flame front wrinkling visible in Fig. 12 may also have other origins than only shear driven turbulence. Hydrodynamic instabilities (referred to as Darrieus-Landau (DL) instabilities) have been shown to have substantial impact on flame front topologies for thin flame fronts at elevated pressures (Klein et al. 2018; Alqallaf et al. 2019). DL instabilities can increase negative curvature, affect strain rate and vorticity patterns and enhance the counter-gradient type of turbulent scalar fluxes (Lamioni et al. 2018). Although it is reported to be difficult to quantify the contribution of DL instabilities in the presence of intense shear forces under turbulent conditions, linear stability analysis may provide an indication whether flames are inherently unstable due to DL instabilities (Matalon 2018; Klein et al. (2018). In the present study, two linear stability analyses are applied to investigate the potential influence of DL instabilities on flame wrinkling. First, the Markstein number $\mathcal{M}$ is calculated for all flame conditions and fuels according to Clavin and Williams (1982) and Peters (1992). If its reciprocal is larger compared to the Bifurcation

Fig. 12 Composition of instantaneous OH-PLIF singleshot images at $\phi=1.05$ and $\operatorname{Re}_{\text {bulk }}=12,000$ for five different fuels at six axial locations $x / D$. The colorbar is in arbitrary units from low (blue) over medium (green) to high (red) $\mathrm{OH}$ signal intensity

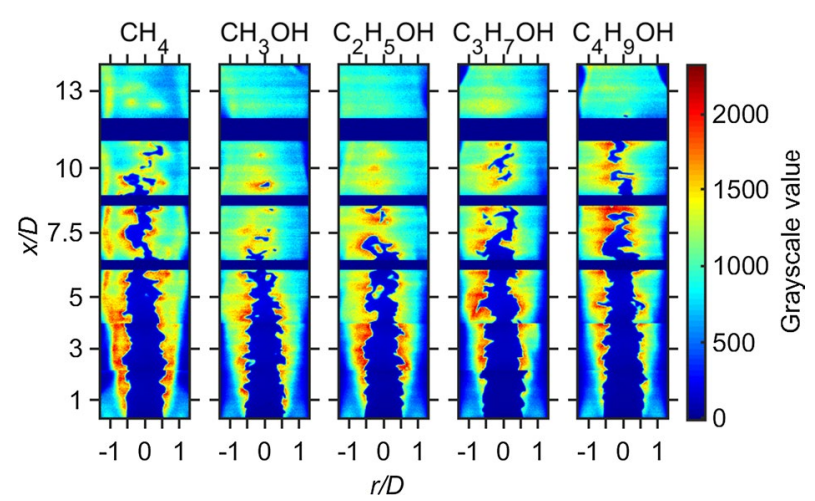


parameter $\mathcal{M}_{c}^{-1}$ Matalon (2018), instability is indicated even for laminar flames, which are generally more prone to become instable by DL instabilities. Second, two critical wavelengths $\lambda_{c}$ are calculated according to either Creta et al. (2016) or Matalon (2018) and subsequently compared to the hydrodynamic length scale (nozzle diameter). Since the critical wavelengths in both definitions are mostly larger than (or even to) the hydrodynamic length scale, results again do not indicate any substantial impact of DL instabilities. $\mathcal{M}, \mathcal{M}_{c}$, and the comparatively more conservative estimates of $\lambda_{c}$ calculated according to Matalon, are summarised in Table 5 in the Appendix. The findings are supported by symmetric PDFs of curvature distributions from the entire flame brush regions (not shown), which furthermore indicate suppression of the DL instability (Klein et al. 2018). To provide further insight into the impact of DL instabilities, a growth rate study according to Sivashinsky (1983) was additionally performed. The magnitude of the growth rates turned out to be more than ten times smaller compared to laminar hydrogen flames at $\phi=0.6$ (Pareja et al. 2011). This indicates that, besides the flow inhomogeneities resulting from high turbulence, fueldependent Lewis-number effects, rather than DL instabilities, dominate flame wrinkling in the present study.

\subsubsection{Flame Surface Density}

Flame lengths presented in Sect. 4.4 vary significantly among the fuels. This indicates that mean reaction rates also differ. As introduced in Sect. 3.3, $\bar{w}$ depends, among other parameters, on $s_{L}$ and the flame surface density $\Sigma$. To evaluate the influence of $\Sigma$ on mean reaction rates, the integrated flame surface density $\Sigma_{2 D \text {,int }}^{*}$ is examined, which allows for a direct assessment of the reaction rate at each axial location. Radial profiles of the $\Sigma_{2 D}$ field (shown in Fig. 5f) are exemplified in Fig. 13 (left). Figure 13 (right) shows the axial profiles of $\Sigma_{2 D \text {,int }}^{*}$ as the result for the integration for two Reynolds-numbers and two equivalence ratios, respectively. At the flame base, values of the $\Sigma_{2 D \text {,int }}^{*}$ close to one indicate a flame almost without any wrinkling and a vertical orientation of the reaction zones. Downstream of the flame base, $\Sigma_{2 D \text {,int }}^{*}$ increases by a factor of more than two as a result of flame wrinkling. It can be imagined as a flame contour having on average more than twice the length of the interrogation box introduced in equation 1. Approaching the tip of the flame brush, the probability for the existence of reaction zones decreases and therefore, once the value of $\Sigma_{2 D \text {,int }}^{*}$ passed unity, the flame is observed only intermittently in the FOV. Finally, where no flame fronts exist, $\Sigma_{2 D \text {, int }}^{*}$ approaches zero. This is the same position where the mean reaction rate $c$ ceases near the flame tip (compare Fig. 5 (e) at $x / D=13$ ). Note, that the values are approximately identical with the flame lengths derived from $\mathrm{CH}^{*}$ chemiluminescence.

For lean conditions upstream of $x / D=4$, all fuel/air mixtures experience the same growth rate in $\Sigma_{2 D, i n t}^{*}$. It is hypothesized that up to this height, the shape of the flame surface is mostly influenced by turbulent shear flow and differences among the fuels do not have a significant influence yet. Downstream of $x / D=4$, the increases of $\Sigma_{2 D \text {,int }}^{*}$ for methane/air, methanol/air and ethanol/air are larger than those of 2-propanol/air and 2-butanol/ air flames. Their earlier culmination of the maxima and subsequent drop towards zero indicates a more intense combustion in an overall smaller volume due to larger wrinkling, despite identical Reynolds-numbers.

When increasing from $\operatorname{Re}_{\text {bulk }}=12,000$ to $R e_{\text {bulk }}=18,000$, an increase in the maxima of the $\Sigma_{2 D \text {,int }}^{*}$ for all fuel/air mixtures is observed. This is expected due to more intense fluctuations in the flow field at larger Reynolds-numbers, which generate more flame 

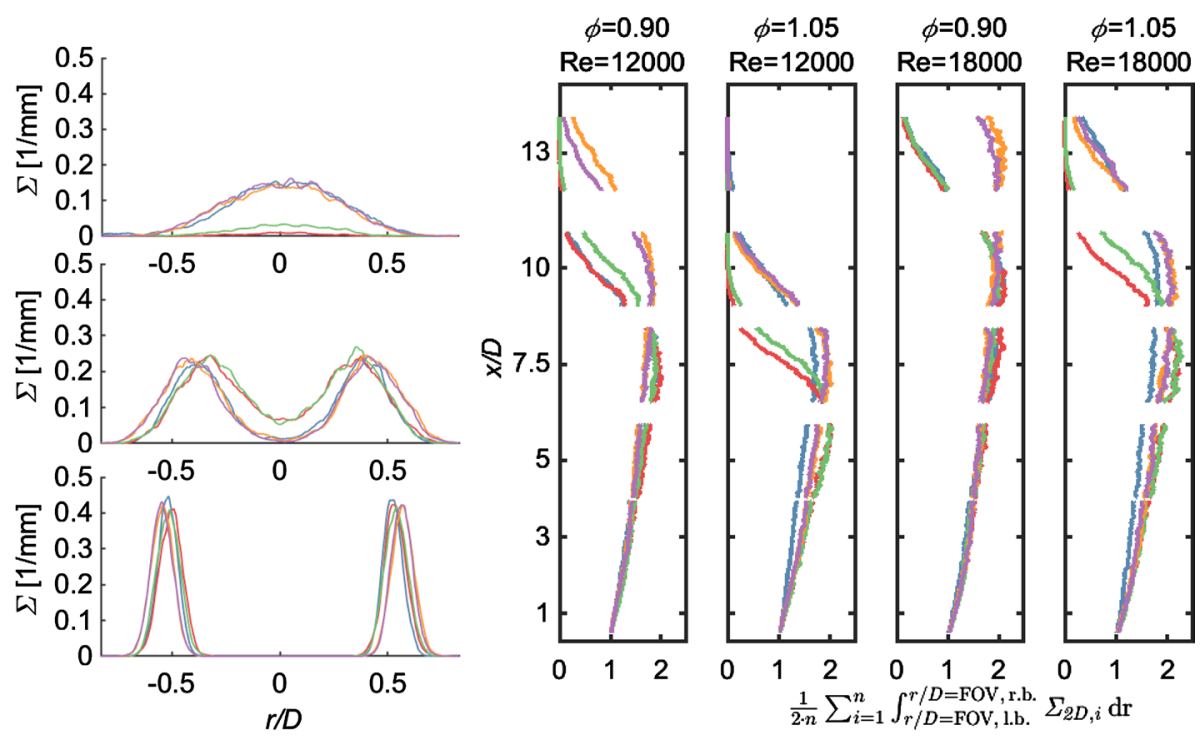

Fig. 13 Left: Exemplary horizontal cross-sections of $\Sigma_{2 D}$ at $x / D=1,5$ and 10 (bottom to top) of $\phi=1.05$ and $\operatorname{Re}_{\text {bulk }}=12,000$. Right: Horizontal integration and ensemble averaging of $\Sigma_{2 D, i}$ as important parameter determining the axial distribution of the mean reaction rate. Methane/air; Methanol/air; E Ethanol/air; 2-Propanol/air; 2-Butanol/air

wrinkling. Additionally, the $\Sigma_{2 D \text {,int }}^{*}$ profiles extend to larger axial heights with higher Reynolds-numbers, which is caused by the generally larger bulk mass flow rates.

An increase in the equivalence ratio to slightly fuel rich conditions at $\phi=1.05$ results for both Reynolds-numbers in a significantly shortened axial progression of $\Sigma_{2 D \text {,int }}^{*}$ for the alcohol/air flames. Methane/air combustion, in contrast, remains almost unchanged. This is evident from Fig. 14, where the same profiles as in Fig. 13 (right) are plotted individually for all fuels and two equivalence ratios. Referring to Fig. 8 and the discussion in the previous section, the effective Lewis-number $\mathrm{Le}_{\text {eff }}$ for methane/air mixtures is only slightly increasing with this variation in equivalence ratio, while for the alco$\mathrm{hol} /$ air mixtures, a substantial drop in $\mathrm{Le}_{\text {eff }}$ is observed. This leads to an augmentation of the transport of reactants, an enhanced flame front wrinkling in particular in negatively curved flame front regions and consequently an increase in the mean reaction rate (Alqallaf et al. 2019). The correlation of the decreasing effective Lewis-numbers and the sudden increase of flame surface density from $\phi=0.9$ to $\phi=1.05$ at lower $x / D$ is striking.

Two intermediate conclusions are drawn from the study of the $\Sigma_{2 D \text {,int }}^{*}$ profiles. First, the overall trends are consistent with the ones of flame lengths derived through $\mathrm{CH}^{*}$ chemiluminescence, as presented in Sect. 4.4. The increased surface area of the flame is likely the most important parameter for the different flame lengths at lean and slightly rich conditions. Second, the significant variation in $\mathrm{Le}_{\text {eff }}$ with increasing equivalence ratio for the alcohol/air mixtures, which is in contrast to the almost constant $\mathrm{Le}_{\text {eff }}$ for methane/air mixtures, is consistent with the larger increases of $\Sigma_{2 D, i n t}^{*}$ and the subsequently shorter flames. It is pointed out that these results support the hypothesis by Carbone et al. (2017) that differing flame lengths of different fuel/air mixtures for lean conditions are caused by different Lewis-numbers. 
Fig. 14 Radially integrated flame surface density $\Sigma_{2 D \text { int }}^{*}$ at $\phi=0.9$ (solid) and $\phi=1.05$ (dashed) and at $\operatorname{Re}_{\text {bulk }}=12,000$ separated by fuel. The change in wrinkling distribution of the alcohol/air mixtures, opposed to the uniform behaviour of methane/air, likely results from Lewis-number effects

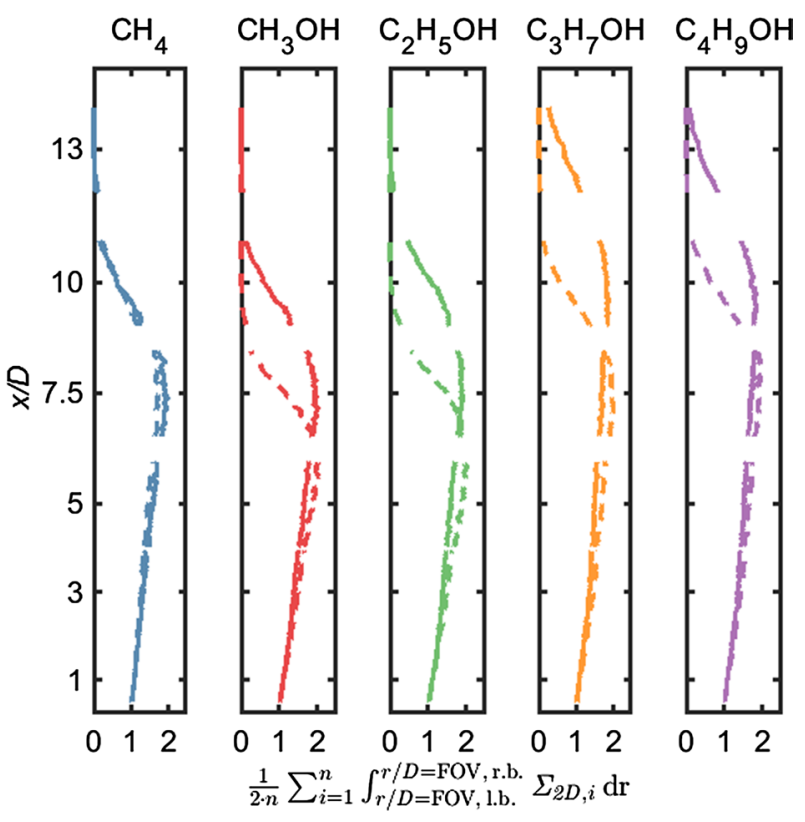

In the following, other than the Lewis-number effects are discussed, which could potentially explain the opposite trends of methane/air and alcohol/air flames. Laminar burning velocities, particularly of the three longer-chained alcohol/air and methane/air mixtures, increase similarly from $\phi=0.9$ to $\phi=1.05$. Therefore, $s_{L}$ is not a key parameter for differences in $\Sigma_{2 D \text {,int }}$. Densities and viscosities are dominated by the high concentration of air in the mixture and vary less than $10 \%$ among the different fuel/air mixtures (Table 3 in the Appendix). Variations in adiabatic flame temperatures are also small (approximately 2\%). Similarly, the maximum temperatures at varying strain rates (see Fig. 7) do not indicate that wrinkling observed for methane/air flames is opposed in its trends compared to the alcohol/air mixtures when switching from $\phi=0.9$ to $\phi=1.05$. Finally, as obvious from Fig. 3, the relative gain of thermal power switching from $\phi=0.9$ to $\phi=1.05$ is similar for all flames, indicating that thermal power likewise is not a major factor.

Although the different global trends observed in $\Sigma_{2 D \text {,int }}^{*}$ for methane/air and the alcohol/air flames are in accordance with the equivalence ratio dependent evolution of the effective Lewis-number, the magnitudes in the $\Sigma_{2 D \text {,int }}^{*}$ profiles do not correlate directly. Despite of their larger Lewis-numbers, the alcohol/air flames show a greater axial increase in flame surface density than the corresponding methane/air flames. This is not 
expected, as their wrinkling should be more dampened by the Lewis-number effects. This is an indication that other fuel-dependent influences than just Lewis-number effects must occur that influence the amount of wrinkling. The local thermo-chemical state can be considered as a further factor influencing flame wrinkling. It determines the microscopic flame structure such as the flame thickness. The determination of local thermochemical states, however, requires multi-scalar measurements such as Raman/Rayleigh scattering. This is beyond the scope of the present study.

\section{Summary}

In this work, selected combustion characteristics of piloted turbulent premixed jet flames operated with methanol/air, ethanol/air, 2-propanol/air, and 2-butanol/air were compared to the ones of methane/air. To ensure well-defined boundary conditions, a novel Temperature Controlled Jet Burner (TCJB) was developed. Operation conditions incorporated a wide range of equivalence ratios and jet Reynolds-numbers up to the blow-off limit. One-dimensional simulations of premixed unstretched flames and counter-flow flames for varying strain rates and equivalence ratios were used to provide most important flame and mixture parameters and to support interpretation of differences observed among the fuels. Chemiluminescence imaging particularly of electronically excited $\mathrm{CH}$-molecules provided information on flame lengths. Planar laser-induced fluorescence of the $\mathrm{OH}$-radical was assessed for determining local flame contours within a two-dimensional plane intersecting the symmetry axis of the burner assembly. This analysis included information on radially integrated flame surface density profiles. Further, other possibly influencing parameters, including laminar burning velocity, viscosity, density, temperature and thermal power as well as DL instability, were considered. Conclusions from these experimental and numerical studies are summarised in the following:

- Resistance against blow-off increased for all flames from lean to fuel rich conditions. For lean conditions, methane/air flames showed higher blow-off velocities than alcohol/air flames. This trend reversed for fuel rich conditions.

- For alcohol/air flames, the stability increased with decreasing chain length, with methanol/air being most stable.

- In premixed jet flames stabilized by a lean pilot, a partially-premixed flame forms in the immediate vicinity of the nozzle, particularly when the jet is operated fuel rich. Supported by other studies, it is assumed that the flame stability is influenced by fuel-specific intermediate chemical species in the reaction zone.

- $\mathrm{CH}^{*}$ chemiluminescence measurements showed significant differences in flame lengths. For increasingly rich conditions, methane/air flames were up to a factor of two taller than corresponding alcohol/air flames. Bulk velocities and laminar burning velocities on their own were not sufficient to explain these differences. 
- A high spatial resolution of $9 \mathrm{lp} / \mathrm{mm}$ for instantaneous OH-PLIF images enabled the measurement of structural features well below the flame front thickness. This data revealed wrinkled flame contours, including pockets of burned/unburned gas located in fresh/exhaust gas regions.

- These pockets appeared as disconnected structures within the two-dimensional intersection of a three-dimensional flame and were included in the analysis of integrated flame surface densities.

- Linear stability analyses revealed that Darrieus-Landau instabilities have little to no influence on the present flames.

- For alcohol/air flames, the effective Lewis-number decreased from fuel lean to rich conditions. As the equivalence ratio increased, the change in the effective Lewis-number was much more pronounced for long-chain alcohols than for short-chain ones. In contrast, the effective Lewis-number of methane/air flames varied considerably less with the equivalence ratio and in the opposite direction.

- Radially integrated flame surface densities were used to assess the overall axial evolution of flame wrinkling. Wrinkling of methanol/air and ethanol/air flames rose significantly faster than those of 2-propanol/air and 2-butanol/air flames for both slightly lean $(\phi=0.9)$ and rich conditions $(\phi=1.05)$. For lean conditions, wrinkling of methane/air flames increased at similar rates than methanol/air and ethanol/air flames, in line with findings for the flame lengths and blow-off limits. Switching the equivalence ratio from lean to fuel rich conditions revealed a change in flame length, flame surface density and thus the reaction rate in accordance with the mixture-dependent variation of the effective Lewis-number.

- Differences in maxima and growth rates of the integrated flame surface densities for the different alcohol/air flames were reflected in according differences in the flame lengths. Different intermediate species formed in the reaction zone may also influence turbulence-chemistry interaction. The evaluation of this hypothesis requires multiscalar measurements of the local thermo-chemical state, which is the topic of ongoing research.

\section{Appendix}

See Tables 3, 4 and 5 . 
Table 3 Important parameters of mixtures and flames derived from 1D unstretched laminar flame calculations: adiabatic temperature $T_{a d}$, unburned mixture density $\rho$, kinematic viscosity $v$, laminar flame thickness $\delta_{f}$ and laminar burning velocity $s_{L}$

\begin{tabular}{|c|c|c|c|c|c|c|}
\hline Equiv. ratio & Parameter & Methane/air & Methanol/air & Ethanol/air & 2-Propanol/air & 2-Butanol/air \\
\hline \multirow[t]{5}{*}{$\phi=0.8$} & $T_{a d}[\mathrm{~K}]$ & 2027 (1992) & 2054 & 2057 & 2055 & 2070 \\
\hline & $\rho\left[\mathrm{kg} / \mathrm{m}^{3}\right]$ & (1.157) 0.990 & 1.036 & 1.058 & 1.065 & 1.069 \\
\hline & $v\left[10^{-5} \mathrm{~m}^{2} / \mathrm{s}\right]$ & (1.539) 2.029 & 1.852 & 1.845 & 1.826 & 1.832 \\
\hline & $\delta_{f}[\mu \mathrm{m}]$ & (534) 498 & 404 & 440 & 417 & 443 \\
\hline & $s_{L}[\mathrm{~cm} / \mathrm{s}]$ & (25.42) 33.64 & 36.93 & 34.75 & 34.51 & 34.89 \\
\hline \multirow[t]{5}{*}{$\phi=0.9$} & $T_{a d}[\mathrm{~K}]$ & (2130) 2160 & 2170 & 2178 & 2182 & 2198 \\
\hline & $\rho\left[\mathrm{kg} / \mathrm{m}^{3}\right]$ & (1.154) 0.986 & 1.037 & 1.061 & 1.070 & 1.075 \\
\hline & $v\left[10^{-5} \mathrm{~m}^{2} / \mathrm{s}\right]$ & (1.540) 2.031 & 1.836 & 1.827 & 1.807 & 1.808 \\
\hline & $\delta_{f}[\mu \mathrm{m}]$ & (472) 444 & 347 & 390 & 374 & 398 \\
\hline & $s_{L}[\mathrm{~cm} / \mathrm{s}]$ & (31.71) 41.24 & 46.77 & 42.67 & 43.80 & 41.89 \\
\hline \multirow[t]{5}{*}{$\phi=1.0$} & $T_{a d}[\mathrm{~K}]$ & (2218) 2244 & 2242 & 2252 & 2262 & 2277 \\
\hline & $\rho\left[\mathrm{kg} / \mathrm{m}^{3}\right]$ & (1.149) 0.982 & 1.039 & 1.065 & 1.075 & 1.080 \\
\hline & $v\left[10^{-5} \mathrm{~m}^{2} / \mathrm{s}\right]$ & (1.542) 2.033 & 1.819 & 1.810 & 1.784 & 1.790 \\
\hline & $\delta_{f}[\mu \mathrm{m}]$ & (444) 419 & 314 & 364 & 351 & 373 \\
\hline & $s_{L}[\mathrm{~cm} / \mathrm{s}]$ & (35.62) 45.89 & 54.47 & 48.04 & 48.74 & 46.78 \\
\hline \multirow[t]{5}{*}{$\phi=1.05$} & $T_{a d}[\mathrm{~K}]$ & (2222) 2249 & 2251 & 2262 & 2271 & 2288 \\
\hline & $\rho\left[\mathrm{kg} / \mathrm{m}^{3}\right]$ & (1.147) 0.980 & 1.039 & 1.067 & 1.077 & 1.082 \\
\hline & $v\left[10^{-5} \mathrm{~m}^{2} / \mathrm{s}\right]$ & (1.542) 2.034 & 1.812 & 1.802 & 1.774 & 1.784 \\
\hline & $\delta_{f}[\mu \mathrm{m}]$ & (436) 413 & 302 & 356 & 342 & 364 \\
\hline & $s_{L}[\mathrm{~cm} / \mathrm{s}]$ & (36.33) 46.68 & 57.28 & 49.51 & 49.92 & 48.06 \\
\hline \multirow[t]{5}{*}{$\phi=1.1$} & $T_{a d}[\mathrm{~K}]$ & (2199) 2230 & 2239 & 2251 & 2256 & 2276 \\
\hline & $\rho\left[\mathrm{kg} / \mathrm{m}^{3}\right]$ & (1.145) 0.978 & 1.040 & 1.069 & 1.080 & 1.085 \\
\hline & $v\left[10^{-5} \mathrm{~m}^{2} / \mathrm{s}\right]$ & (1.543) 2.035 & 1.805 & 1.793 & 1.765 & 1.772 \\
\hline & $\delta_{f}[\mu \mathrm{m}]$ & (434) 411 & 291 & 349 & 336 & 357 \\
\hline & $s_{L}[\mathrm{~cm} / \mathrm{s}]$ & $(35.97)$ & 59.35 & 50.18 & 50.48 & 48.37 \\
\hline \multirow[t]{5}{*}{$\phi=1.2$} & $T_{a d}[\mathrm{~K}]$ & (2126) 2159 & 2183 & 2192 & 2190 & 2213 \\
\hline & $\rho\left[\mathrm{kg} / \mathrm{m}^{3}\right]$ & 0.974 & 1.041 & 1.072 & 1.084 & 1.090 \\
\hline & $v\left[10^{-5} \mathrm{~m}^{2} / \mathrm{s}\right]$ & (1.544) 2.037 & 1.790 & 1.777 & 1.747 & 1.755 \\
\hline & $\delta_{f}[\mu \mathrm{m}]$ & (471) 440 & 277 & 347 & 334 & 356 \\
\hline & $s_{L}[\mathrm{~cm} / \mathrm{s}]$ & (31.42) 40.95 & 60.92 & 48.55 & 48.53 & 45.94 \\
\hline \multirow[t]{5}{*}{$\phi=1.3$} & $T_{a d}[\mathrm{~K}]$ & (2047) 2080 & 2118 & 2119 & 2114 & 2138 \\
\hline & $\rho\left[\mathrm{kg} / \mathrm{m}^{3}\right]$ & 0.971 & 1.042 & 1.076 & 1.089 & 1.096 \\
\hline & $v\left[10^{-5} \mathrm{~m}^{2} / \mathrm{s}\right]$ & (1.546) 2.039 & 1.775 & 1.760 & 1.729 & 1.732 \\
\hline & $\delta_{f}[\mu \mathrm{m}]$ & (622) 568 & 277 & 372 & 362 & 389 \\
\hline & $s_{L}[\mathrm{~cm} / \mathrm{s}]$ & (21.98) 29.74 & 58.82 & 42.99 & 41.91 & 39.56 \\
\hline \multirow[t]{5}{*}{$\phi=1.4$} & $T_{a d}[\mathrm{~K}]$ & (1970) 2003 & 2053 & 2048 & 2039 & 2063 \\
\hline & $\rho\left[\mathrm{kg} / \mathrm{m}^{3}\right]$ & (1.132) 0.967 & 1.044 & 1.080 & 1.093 & 1.101 \\
\hline & $v\left[10^{-5} \mathrm{~m}^{2} / \mathrm{s}\right]$ & (1.547) 2.041 & 1.762 & 1.743 & 1.712 & 1.716 \\
\hline & $\delta_{f}[\mu \mathrm{m}]$ & (1037) 894 & 295 & 443 & 439 & 480 \\
\hline & $s_{L}[\mathrm{~cm} / \mathrm{s}]$ & 17.97 (12.81) & 53.15 & 33.87 & 32.42 & 29.88 \\
\hline
\end{tabular}


Table 3 (continued)

\begin{tabular}{lllllll}
\hline Equiv. ratio & Parameter & Methane/air & Methanol/air & Ethanol/air & 2-Propanol/air & 2-Butanol/air \\
\hline$\phi=1.5$ & $T_{a d}[\mathrm{~K}]$ & $(1900) 1933$ & 1991 & 1978 & 1966 & 1990 \\
& $\rho\left[\mathrm{kg} / \mathrm{m}^{3}\right]$ & $(1.126) 0.963$ & 1.045 & 1.084 & 1.098 & 1.106 \\
& $v\left[10^{-5} \mathrm{~m}^{2} / \mathrm{s}\right]$ & $(1.548) 2.043$ & 1.748 & 1.728 & 1.695 & 1.699 \\
& $\delta_{f}[\mu \mathrm{m}]$ & $(1374) 1214$ & 336 & 593 & 584 & 655 \\
& $s_{L}[\mathrm{~cm} / \mathrm{s}]$ & $(9.41) 12.83$ & 44.86 & 24.03 & 22.93 & 20.44 \\
\hline
\end{tabular}

For methane/air, parameters are given for premix temperatures of $293 \mathrm{~K}$ (brackets) and $343 \mathrm{~K}$, respectively. All other mixtures are at $343 \mathrm{~K}$

Table 4 Gas composition of pilot flames for respective jet fuels

\begin{tabular}{llllll}
\hline $\begin{array}{l}\text { Contents of } \ldots \\
\text { [mass-\%] }\end{array}$ & Methane/air & Methanol/air & Ethanol/air & 2-Propanol/air & 2-Butanol/air \\
\hline Air & 76.19 & 77.84 & 79.55 & 80.29 & 80.55 \\
$\mathrm{~N}_{2}$ & 8.41 & 1.66 & 4.31 & 5.17 & 5.72 \\
$\mathrm{H}_{2}$ & 10.93 & 14.22 & 10.18 & 8.70 & 7.96 \\
$\mathrm{CO}_{2}$ & 2.47 & 4.62 & 3.48 & 3.04 & 2.84 \\
$\mathrm{C}_{2} \mathrm{H}_{2}$ & 2.00 & 1.66 & 2.48 & 2.79 & 2.93 \\
\hline
\end{tabular}

Table 5 Parameters indicating Darrieus-Landau instabilities

\begin{tabular}{lllllll}
\hline Equiv. ratio & Parameter & Methane/air & Methanol/air & Ethanol/air & 2-Propanol/air & 2-Butanol/air \\
\hline$\phi=0.8$ & $\mathcal{M}$ & 2.056 & 2.935 & 3.996 & 4.978 & 5.851 \\
& $\mathcal{M}_{c}$ & 0.932 & 0.994 & 0.998 & 0.997 & 1.005 \\
& $\lambda_{c}[\mathrm{~m}]$ & 0.0155 & 0.0177 & 0.0263 & 0.0330 & 0.0366 \\
$\phi=0.9$ & $\mathcal{M}$ & 2.064 & 2.936 & 3.997 & 4.962 & 5.842 \\
& $\mathcal{M}_{c}$ & 0.997 & 1.059 & 1.067 & 1.070 & 1.078 \\
$\phi=1.0$ & $\lambda_{c}[\mathrm{~m}]$ & 0.0142 & 0.0149 & 0.0225 & 0.0292 & 0.0323 \\
& $\mathcal{M}^{*}$ & 2.071 & 2.932 & 3.989 & 4.951 & 5.837 \\
& $\mathcal{M}_{c}$ & 1.041 & 1.107 & 1.117 & 1.122 & 1.131 \\
& $\lambda_{c}[\mathrm{~m}]$ & 0.0141 & 0.0127 & 0.0185 & 0.0238 & 0.0257 \\
$\phi=1.05$ & $\mathcal{M}^{*} 1.1$ & 2.080 & 2.927 & 3.980 & 4.951 & 5.843 \\
& $\mathcal{M}_{c}$ & 1.050 & 1.119 & 1.131 & 1.134 & 1.144 \\
& $\lambda_{c}[\mathrm{~m}]$ & 0.0143 & 0.0115 & 0.0161 & 0.0203 & 0.0214 \\
& $\mathcal{M}^{*} 1.2$ & 2.088 & 2.928 & 3.975 & 4.956 & 5.835 \\
& $\mathcal{M}_{c}$ & 1.048 & 1.123 & 1.136 & 1.140 & 1.152 \\
& $\lambda_{c}[\mathrm{~m}]$ & 0.0143 & 0.0106 & 0.0145 & 0.0171 & 0.0175 \\
& $\mathcal{M}^{*}$ & 2.096 & 2.926 & 3.961 & 4.936 & 5.825 \\
& $\mathcal{M}_{c}$ & 1.032 & 1.116 & 1.113 & 1.131 & 1.145 \\
& $\lambda_{c}[\mathrm{~m}]$ & 0.0154 & 0.0096 & 0.0132 & 0.0150 & 0.0149 \\
\hline
\end{tabular}


Table 5 (continued)

\begin{tabular}{lllllll}
\hline Equiv. ratio & Parameter & Methane/air & Methanol/air & Ethanol/air & 2-Propanol/air & 2-Butanol/air \\
\hline$\phi=1.3$ & $\mathcal{M}$ & 2.104 & 2.922 & 3.951 & 4.907 & 5.787 \\
& $\mathcal{M}_{c}$ & 1.011 & 1.104 & 1.116 & 1.117 & 1.131 \\
& $\lambda_{c}[\mathrm{~m}]$ & 0.0204 & 0.0094 & 0.0164 & 0.0153 & 0.0149 \\
$\phi=1.4$ & $\mathcal{M}$ & 2.113 & 2.919 & 3.942 & 4.856 & 5.728 \\
& $\mathcal{M}_{c}$ & 0.989 & 1.090 & 1.100 & 1.100 & 1.116 \\
& $\lambda_{c}[\mathrm{~m}]$ & 0.0333 & 0.0097 & 0.0153 & 0.0178 & 0.0169 \\
$\phi=1.5$ & $\mathcal{M}$ & 2.122 & 2.916 & 3.927 & 4.754 & 5.589 \\
& $\mathcal{M}_{c}$ & 0.966 & 1.076 & 1.085 & 1.084 & 1.100 \\
& $\lambda_{c}[\mathrm{~m}]$ & 0.0443 & 0.0108 & 0.0195 & 0.0228 & 0.0211 \\
\hline
\end{tabular}

If the Markstein number $\mathcal{M}$ is greater than $\mathcal{M}_{c}$, laminar flames are expected to be stable (Matalon 2018). Using the critical wavelength $\lambda_{c}$ as an alternative parameter, for instability, $\lambda_{c}$ should be larger than the hydrodynamic length scale, in this case the nozzle diameter $(D=0.0114 \mathrm{~m})$ (Klein et al. 2018). Based on these indicators, in the present study, DL instabilities have a minor impact on flame topologies

Acknowledgements Open Access funding provided by Projekt DEAL. We greatfully acknowledge Prof. Simone Hochgreb for the provision of code to analyse the OH-PLIF images originally written by $\mathbf{M}$. Sweeney. We furthermore gratefully acknowledge financial support by the Deutsche Forschungsgemeinschaft (DFG) through GE 2523/2-1 and DR 374/17-1. A. Dreizler was financially supported by the Gottfried Wilhelm Leibniz-Preis (DFG). D. Geyer was financially supported by the European Regional Development Fund (ERDF, project-nr.: FPG991 0005/2019) and by the Zentrum für Forschung und Entwicklung (ZFE) of the Darmstadt University of Applied Sciences.

\section{Compliances with Ethical Standards}

Conflict of interest The authors declare that they have no Conflict of interest.

Open Access This article is licensed under a Creative Commons Attribution 4.0 International License, which permits use, sharing, adaptation, distribution and reproduction in any medium or format, as long as you give appropriate credit to the original author(s) and the source, provide a link to the Creative Commons licence, and indicate if changes were made. The images or other third party material in this article are included in the article's Creative Commons licence, unless indicated otherwise in a credit line to the material. If material is not included in the article's Creative Commons licence and your intended use is not permitted by statutory regulation or exceeds the permitted use, you will need to obtain permission directly from the copyright holder. To view a copy of this licence, visit http://creativecommons.org/licenses/by/4.0/.

\section{References}

Addabbo, R., Bechtold, J.K., Matalon, M.: Wrinkling of spherically expanding flames. Proc. Combust. Inst. 29(2), 1527-1535 (2002). https://doi.org/10.1016/S1540-7489(02)80187-0

Alqallaf, A., Klein, M., Chakraborty, N.: Effects of lewis number on the evolution of curvature in spherically expanding turbulent premixed flames. Fluids 4(1), 12 (2019). https://doi.org/10.3390/fluids4010 012

Bell, J.H., Mehta, R.D.: Contraction design for small low-speed wind tunnels. Joint Institute for Aeronautics and Acoustics (1988). https://ntrs.nasa.gov/search.jsp?R=19890004382

Bray, K.N.C.: Studies of the turbulent burning velocity. Proc. R. Soc. A Math. Phys. Eng. Sci. 431(1882), 315-335 (1990). https://doi.org/10.1098/rspa.1990.0133 
Carbone, F., Smolke, J.L., Fincham, A.M., Egolfopoulos, F.N.: Comparative behavior of piloted turbulent premixed jet flames of c1-c8 hydrocarbons. Combust. Flame 180, 88-101 (2017). https://doi. org/10.1016/j.combustflame.2017.02.030

Clavin, P., Williams, F.A.: Effects of molecular diffusion and of thermal expansion on the structure and dynamics of premixed flames in turbulent flows of large scale and low intensity. J. Fluid Mech. 116, 251-282 (1982). https://doi.org/10.1017/S0022112082000457

Coriton, B., Im, S.K., Gamba, M., Frank, J.H.: Flow field and scalar measurements in a series of turbulent partially-premixed dimethyl ether/air jet flames. Combust. Flame 180, 40-52 (2017). https:// doi.org/10.1016/j.combustflame.2017.02.014

Creta, F., Lamioni, R., Lapenna, P.E., Troiani, G.: Interplay of Darrieus-Landau instability and weak turbulence in premixed flame propagation. Phys. Rev. E 94(5-1), 053102 (2016). https://doi. org/10.1103/PhysRevE.94.053102

Donbar, J.M., Driscoll, J.F., Carter, C.D.: Reaction zone structure in turbulent nonpremixed jet flamesfrom ch-oh plif images. Combust. Flame 122(1-2), 1-19 (2000). https://doi.org/10.1016/S0010 $-2180(00) 00098-5$

Dunn, M.J., Masri, A.R., Bilger, R.W.: A new piloted premixed jet burner to study strong finite-rate chemistry effects. Combust. Flame 151(1-2), 46-60 (2007). https://doi.org/10.1016/j.combustfla me.2007.05.010

Eitel, F., Pareja, J., Johchi, A., Böhm, B., Geyer, D., Dreizler, A.: Temporal evolution of auto-ignition of ethylene and methane jets propagating into a turbulent hot air co-flow vitiated with no x. Combust. Flame 177, 193-206 (2017). https://doi.org/10.1016/j.combustflame.2016.12.009

Farida, A.Z., Kumaran, K., Shet, U.S., Sundararajan, T.: Stability of partially premixed tubular burner flames with co-flow and external swirl-air. 5th Asia-Pacific Conference on Combustion (2005)

Filatyev, S.A., Driscoll, J.F., Carter, C.D., Donbar, J.M.: Measured properties of turbulent premixed flames for model assessment, including burning velocities, stretch rates, and surface densities. Combust. Flame 141(1-2), 1-21 (2005). https://doi.org/10.1016/j.combustflame.2004.07.010

Frassoldati, A., Grana, R., Faravelli, T., Ranzi, E., Oßwald, P., Kohse-Höinghaus, K.: Detailed kinetic modeling of the combustion of the four butanol isomers in premixed low-pressure flames. Combust. Flame 159(7), 2295-2311 (2012). https://doi.org/10.1016/j.combustflame.2012.03.002

Guiberti, T.F., Cutcher, H., Roberts, W.L., Masri, A.R.: Influence of pilot flame parameters on the stability of turbulent jet flames. Energy Fuels 31(3), 2128-2137 (2017a). https://doi.org/10.1021/acs. energyfuels.6b02052

Guiberti, T.F., Juddoo, M., Lacoste, D.A., Dunn, M.J., Roberts, W.L., Masri, A.R.: Fuel effects on the stability of turbulent flames with compositionally inhomogeneous inlets. Proc. Combust. Inst. 36(2), 1777-1784 (2017b). https://doi.org/10.1016/j.proci.2016.08.051

Hartl, S., Geyer, D., Dreizler, A., Magnotti, G., Barlow, R.S., Hasse, C.: Regime identification from raman/rayleigh line measurements in partially premixed flames. Combust. Flame 189, 126-141 (2018). https://doi.org/10.1016/j.combustflame.2017.10.024

Klein, M., Nachtigal, H., Hansinger, M., Pfitzner, M., Chakraborty, N.: Flame curvature distribution in high pressure turbulent bunsen premixed flames. Flow Turbul. Combust. 101(4), 1173-1187 (2018). https://doi.org/10.1007/s10494-018-9951-1

Kohse-Höinghaus, K., Oßwald, P., Cool, T.A., Kasper, T., Hansen, N., Qi, F., Westbrook, C.K., Westmoreland, P.R.: Biofuel combustion chemistry: from ethanol to biodiesel. Angew. Chem. Int. Ed. 49(21), 3572-3597 (2010). https://doi.org/10.1002/anie.200905335

Kojima, J., Ikeda, Y., Nakajima, T.: Spatially resolved measurement of $\mathrm{OH}^{*}, \mathrm{CH}^{*}$, and C2* chemiluminescence in the reaction zone of laminar methane/air premixed flames. Proc. Combust. Inst. 28(2), 1757-1764 (2000). https://doi.org/10.1016/S0082-0784(00)80577-9

Lamioni, R., Lapenna, P.E., Troiani, G., Creta, F.: Flame induced flow features in the presence of darrieus-landau instability. Flow Turbul. Combust. 101(4), 1137-1155 (2018). https://doi.org/10.1007/ s10494-018-9936-0

Law, C.K.: Combustion Physics, 1st edn. Cambridge University Press, Cambridge (2010)

Law, C., Sung, C.: Structure, aerodynamics, and geometry of premixed flamelets. Prog. Energy Combust. Sci. 26(4-6), 459-505 (2000). https://doi.org/10.1016/S0360-1285(00)00018-6

Law, C.K., Zhu, D.L., Yu, G.: Propagation and extinction of stretched premixed flames. Symp. Int. Combust. 21(1), 1419-1426 (1988). https://doi.org/10.1016/S0082-0784(88)80374-6

Lewis, B., von Elbe, G.: Combustion, Flames and Explosions of Gases, Third edn. Academic Press, New York (1987)

Li, J., Zhao, Z., Kazakov, A., Chaos, M., Dryer, F.L., Scire, J.J.: A comprehensive kinetic mechanism for $\mathrm{CO}, \mathrm{CH}_{2} \mathrm{O}$, and $\mathrm{CH}_{3} \mathrm{OH}$ combustion. Int. J. Chem. Kinet. 39(3), 109-136 (2007). https://doi. org/10.1002/kin.20218 
Masri, A.R., Dibble, R.W., Barlow, R.S.: The structure of turbulent nonpremixed flames revealed by raman-rayleigh-lif measurements. Prog. Energy Combust. Sci. 22(4), 307-362 (1996). https://doi. org/10.1016/S0360-1285(96)00009-3

Matalon, M.: The Darrieus-Landau instability of premixed flames. Fluid Dyn. Res. 50(5), 051412 (2018). https://doi.org/10.1088/1873-7005/aab510

Nauert, A.: Laseroptische Untersuchungen an verdrallten Vormischflammen: Zugl.: Darmstadt, Techn. Univ., Diss, Fortschritt-Berichte VDI Reihe 6, Energietechnik, vol. 585, als ms. gedr edn. VDI-Verl., Düsseldorf (2009)

OECD: Renewables 2018 (2018). https://doi.org/10.1787/re_mar-2018-en

Olm, C., Varga, T., Valkó, É., Hartl, S., Hasse, C., Turányi, T.: Development of an ethanol combustion mechanism based on a hierarchical optimization approach. Int. J. Chem. Kinet. 48(8), 423-441 (2016). https://doi.org/10.1002/kin.20998

Pareja, J., Burbano, H.J., Amell, A., Carvajal, J.: Laminar burning velocities and flame stability analysis of hydrogen/air premixed flames at low pressure. Int. J. Hydrogen Energy 36(10), 6317-6324 (2011). https://doi.org/10.1016/j.ijhydene.2011.02.042

Peters, N.: A spectral closure for premixed turbulent combustion in the flamelet regime. J. Fluid Mech. 242, 611-629 (1992). https://doi.org/10.1017/S0022112092002519

Pretzier, G.: A new method for numerical abel-inversion. Zeitschrift für Naturforschung A 46(7), 639-641 (1991). https://doi.org/10.1515/zna-1991-0715

Sadanandan, R., Stöhr, M., Meier, W.: Simultaneous oh-plif and piv measurements in a gas turbine model combustor. Appl. Phys. B 90(3-4), 609-618 (2008). https://doi.org/10.1007/s00340-007-2928-8

Samaniego, J.M., Egolfopoulos, F.N., Bowman, C.T.: $\mathrm{CO}_{2}{ }^{*}$ chemiluminescence in premixed flames. Combust. Sci. Technol. 109(1-6), 183-203 (1995). https://doi.org/10.1080/00102209508951901

Sarathy, S.M., Oßwald, P., Hansen, N., Kohse-Höinghaus, K.: Alcohol combustion chemistry. Prog. Energy Combust. Sci. 44, 40-102 (2014). https://doi.org/10.1016/j.pecs.2014.04.003

Schneider, S., Geyer, D., Magnotti, G., Dunn, M.J., Barlow, R.S., Dreizler, A.: Structure of a stratified CH4 flame with H2 addition. Proc. Combust. Inst. 37(2), 2307-2315 (2019). https://doi.org/10.1016/j.proci .2018.06.205

Shepherd, I.G.: Flame surface density and burning rate in premixed turbulent flames. Symp. Int. Combust. 26(1), 373-379 (1996). https://doi.org/10.1016/S0082-0784(96)80238-4

Sivashinsky, G.I.: Instabilities, pattern formation, and turbulence in flames. Annu. Rev. Fluid Mech. 15(1), 179-199 (1983). https://doi.org/10.1146/annurev.fl.15.010183.001143

Smith, G., Bowman, T., Frenklach, M.: Gri30 (2019). http://combustion.berkeley.edu/gri-mech/

Smolke, J., Lapointe, S., Paxton, L., Blanquart, G., Carbone, F., Fincham, A.M., Egolfopoulos, F.N.: Experimental and numerical studies of fuel and hydrodynamic effects on piloted turbulent premixed jet flames. Proc. Combust. Inst. 36(2), 1877-1884 (2017). https://doi.org/10.1016/j.proci.2016.07.127

Sweeney, M.S., Hochgreb, S., Dunn, M.J., Barlow, R.S.: A comparative analysis of flame surface density metrics inpremixed and stratified flames. Proc. Combust. Inst. 33(1), 1419-1427 (2011). https://doi. org/10.1016/j.proci.2010.05.069

Tamadonfar, P., Gülder, Ö.L.: Effects of mixture composition and turbulence intensity on flame front structure and burning velocities of premixed turbulent hydrocarbon/air bunsen flames. Combust. Flame 162(12), 4417-4441 (2015). https://doi.org/10.1016/j.combustflame.2015.08.009

Trouvé, A., Poinsot, T.: The evolution equation for the flame surface density in turbulent premixed combustion. J. Fluid Mech. 278, 1-31 (1994). https://doi.org/10.1017/S0022112094003599

Veloo, P.S., Wang, Y.L., Egolfopoulos, F.N., Westbrook, C.K.: A comparative experimental and computational study of methanol, ethanol, and n-butanol flames. Combust. Flame 157(10), 1989-2004 (2010). https://doi.org/10.1016/j.combustflame.2010.04.001

Veynante, D., Trouvé, A., Bray, K.N.C., Mantel, T.: Gradient and counter-gradient scalar transport in turbulent premixed flames. J. Fluid Mech. 332, 263-293 (1997). https://doi.org/10.1017/S00221120960040 65

Watson, G.M., Versailles, P., Bergthorson, J.M.: No formation in rich premixed flames of C1-C4 alkanes and alcohols. Proc. Combust. Inst. 36(1), 627-635 (2017). https://doi.org/10.1016/j.proci.2016.06.108

Zschutschke, A., Messig, D., Scholtissek, A., Hasse, C.: Universal Laminar Flame Solver (ULF) (2017). https://doi.org/10.6084/m9.figshare.5119855.v2 